\title{
O poder da reputação: evidências do efeito big four sobre a opinião do auditor
}

The power of reputation: evidences of the big four effect on auditor's opinion

El poder de la reputación: evidencias del efecto big four en la opinión del auditor

\section{Vagner Antônio Marques}

Doutor em Administração pela Universidade Federal de Minas Gerais

Professor Adjunto do Departamento de Ciências Contábeis da UFES

Endereço: Av. Fernando Ferrari, 514 - Goiabeiras

CEP: 29075-910 - Vitória/ES - Brasil

E-mail:vmarques@ufes.br

Telefone: (27) 4009-2602

\section{Luiz Cláudio Louzada}

Doutor em Administração pela Universidade Federal de Minas Gerais

Professor Adjunto do Departamento de Ciências Contábeis da UFES

Endereço: Av. Fernando Ferrari, 514 - Goiabeiras

CEP: 29075-910 - Vitória/ES - Brasil

E-mail: louzadalvi@gmail.com

Telefone: (27) 4009-2602

\section{Hudson Fernandes Amaral}

Doutor em Administração pela Université Pierre Mendes France - Grenoble (França).

Professor Titular do Centro Universitário Unihorizontes - MG

Professor Catedrático Visitante do ISEG/ULISBOA (Portugal).

Endereço: Av. Antônio Carlos, 6627 - Prédio FACE - Sala: 4030

CEP: 31.270-901 - Belo Horizonte/MG - Brasil.

E-mail: hfamaral@face.ufmg.br

Telefone: (31) 34097031

\section{Antônio Artur de Souza}

$\mathrm{PhD}$ em Management Science pela University of Lancaster

Professor Associado do DCAD/FACE/UFMG (Brasil).

Professor Catedrático Visitante do ISEG/ULISBOA (Portugal).

Endereço: Av. Antônio Carlos, 6627 - Prédio FACE - Sala: 4097

CEP: 31.270-901 - Belo Horizonte/MG - Brasil.

E-mail: artur@face.ufmg.br

Telefone: (31) 34097259

Artigo recebido em 17/10/2016. Revisado por pares em 05/07/2017. Reformulado em 11/11/2017. Recomendado para publicação em 15/06/2018 por Carlos Eduardo Facin Lavarda (Editor-Chefe). Publicado em 30/06/2018. 


\section{Resumo}

O presente trabalho analisou o efeito das Big Four sobre o tipo de opinião dos auditores. O estudo, descritivo, documental e quantitativo, analisou relatórios anuais de 504 empresas listadas na $[\mathrm{B}]^{3}$ no período de 2002-2012 através de estatística descritiva e regressão com dados em painel. Observou-se existir uma concentração do mercado de auditoria, pois as Big Four chegaram a auditar $75 \%$ das empresas, o que pode prejudicar a independência do auditor. Em média, a probabilidade de uma empresa listada receber um relatório modificado é 6,20\%. Verificou-se ainda que ser auditado por uma Big Four e possuir Níveis Diferenciados de Governança reduzem a probabilidade de se receber uma opinião modificada. Por sua vez, empresas que apresentam prejuízos e a adoção do IFRS Parcial aumentaram a probabilidade de receberem uma opinião modificada. Estes resultados contribuem com os reguladores, investidores e auditores na sinalização dos fatores que afetam o tipo de opinião do auditor.

Palavras-chaves: Big Four; Auditoria Independente; Opinião do auditor

\section{Abstract}

The present study analyzed the effect of the Big Four audit firms on the type of auditor's opinion. The research was descriptive, documental and quantitative, based on descriptive statistics and regression with panel data. It consisted in an analysis of the annual reports of 504 companies listed in the Brazilian stock exchange during the period from 2002 to 2012. It was possible to conclude that there is a concentration in the Brazilian audit market, since the Big Four audit firms managed to work with $75 \%$ of the companies, which could hamper the auditor's independence. On average, the probability of a listed company receiving a qualified report is $6.20 \%$. It was also found that being audited by a Big Four and having differentiated Levels of Governance reduces the probability of receiving a qualified auditor's opinion. In turn, companies that incur losses and the adoption of Partial IFRS are associated to a higher likelihood of receiving a qualified opinion. These results may contribute to regulators, investors and auditors in signaling out the factors that affect the auditor's type of opinion.

Keywords: Big Four; Independent Audit; Auditor's opinion

\section{Resumen}

El presente estudio analizó el efecto de las cuatro firmas de auditoría en el tipo de opinión del auditor. La investigación fue descriptiva, documental y cuantitativa, basada en estadisticas descriptivas y regresión con datos de panel. Consistió en un análisis de los informes anuales de 504 empresas que cotizan en la bolsa de valores brasileña durante el periodo de 2002 a 2012. Se pudo concluir que hay una concentración en el mercado de auditoría brasileño, ya que las cuatro firmas auditoras lograron trabajar con el 75\% de las empresas, lo que podría obstaculizar la independencia del auditor. En promedio, la probabilidad de que una empresa cotizada reciba un informe calificado es del $6.20 \%$. También se encontró que ser auditado por un Big Four y tener niveles de gobierno diferenciados reduce la probabilidad de recibir la opinión de un auditor calificado. A su vez, las compañías que incurren en pérdidas y la adopción de NIIF Parciales están asociadas a una mayor probabilidad de recibir una opinión calificada. Estos resultados pueden contribuir a que los reguladores, los inversores y los auditores señalicen los factores que afectan el tipo de opinión del auditor.

Palabras clave: Big Four; Auditoría Independiente; Opinión del auditor 


\section{Introdução}

A firma como um nexo de contratos que visa à maximização de valor para os acionistas demanda informações necessárias para se avaliar o seu nível de eficiência e decidir sobre isso (SUNDER, 2014). Dentre essas informações, aquelas divulgadas a partir da contabilidade são essenciais para o mercado de capitais e de crédito, pois possibilitam que os diversos usuários ajustem suas expectativas sobre o desempenho futuro das companhias (BEAVER, 1998).

Ocorre que, para o adequado cumprimento do seu objetivo, as informações contábeis precisam ser fidedignas, não viesadas e livres de erros. Entretanto, fatores como a natureza dos indivíduos, as fragilidades dos contratos e a flexibilidade das normas podem prejudicar a qualidade das informações contábeis (JENSEN e MECKLING, 1994; COASE, 1937; WATTS, 1992). Esses fatores, associados aos Problemas de Agência (JENSEN e MECKLING, 1976), tratam-se de eventos originados da característica automaximizadora dos indivíduos que, aliados à incompletude dos contratos e à flexibilidade das normas de contabilidade, possibilitam aos agentes (gestores) agirem oportunisticamente, podendo acarretar prejuízos aos principais (acionistas) e às demais partes interessadas (BROWN, BEEKES e VERHOEVEN, 2011).

Para reduzir o risco de ocorrência desses episódios, as empresas utilizam-se da estrutura de governança corporativa. Di Pietra, McLeay e Ronen (2014) definem governança corporativa como todo conjunto de mecanismos, internos ou externos, que visam mitigar os problemas de agência, alinhando os interesses entre principal-agente (principal-stakeholders, agentestakeholders).

Dentre os diversos mecanismos de governança possíveis, destaca-se a auditoria independente. Trata-se do processo de certificação quanto à adequação das demonstrações financeiras, divulgadas através do relatório de auditoria, que pode ser modificado ou não modificado (Blandon \& Bosch, 2013). O relatório será não modificado quando as demonstrações contábeis estiverem adequadamente elaboradas nos principais aspectos relevantes. Por sua vez, o relatório será modificado quando: (i) houver distorção material não generalizada nas demonstrações, (ii) houver distorções generalizadas nas demonstrações e (iii) não houver condições de obter evidências quanto à (in) adequação das demonstrações contábeis (BOYNTON; JOHNSON; KELL, 2002).

Segundo Mckee (2014), as normas de auditoria vigentes exigem que o auditor, durante o planejamento dos trabalhos, avalie o risco de erro material ou fraude. Entretanto, a falta de experiência em casos de fraudes financeiras dificulta o processo de identificação de fatores indicadores desses eventos. Além disso, a opinião do auditor contribui para que os usuários tenham maior confiança nas informações financeiras divulgadas, possibilitando-lhes decidirem da forma mais acertada possível. Dart (2011) destaca que a opinião do auditor é essencial para a redução da assimetria informacional, pois certifica o nível de qualidade mínima esperada acerca das demonstrações financeiras divulgadas na medida em que se cumprem as normas vigentes aplicáveis à entidade auditada.

Apesar de sua relevância, Kranacher (2009) observa que as discussões sobre a opinião do auditor têm sido pequenas e, por vezes, negligenciadas. Complementa a autora que as diversas republicações e escândalos são evidências de que os auditores não conseguem assegurar integralmente a correção das demonstrações contábeis.

No contexto brasileiro, a auditoria se desenvolveu a partir do início do século XX com a vinda de empresas estrangeiras, trazendo consigo as principais firmas de auditoria, denominadas Big Four (RICARDINO; CARVALHO, 2004). As Big Four são as quatro grandes empresas de auditoria "internacionais", a saber: Delloite, KPMG, Ernest Young e PriceWatherhouse. Até o ano de 2001, essas empresas formavam um grupo de 05 e, na década de 1990, o grupo era composto por 06. Segundo Cooper et al. (1998), em 1997, houve a 
incorporação da Coopers\&Librand pela PriceWatherhouse e, em 2001, devido ao escândalo da Enron, a Artur Andersen foi incorporada pelas demais nos diversos países em que mantinha contratos (EISEMBERG; MACEY, 2004).

Além disso, existem evidências de que há uma concentração do mercado de auditoria das empresas listadas entre as quatro maiores. Francis, Michas e Seavey (2011) afirmam que, nos últimos anos, tem-se observado a concentração do mercado de auditoria entre as Big Four, em grande medida, fruto da reputação adquirida por essas companhias. Porém, essa concentração pode provocar efeitos adversos, tais como perda de independência e da qualidade da auditoria, aumentando a probabilidade do aumento do gerenciamento de resultados, além do problema de seleção adversa, inerente à informação contábil de menor qualidade.

Diante desse contexto, o presente estudo buscou responder à seguinte pergunta: Qual a influência das Big Four no tipo de relatório de auditoria emitido no contexto brasileiro? Complementarmente, procurou responder: Qual a probabilidade de se receberem relatórios modificados pelas empresas participantes da $[\mathbf{B}]^{3}$ ? O objetivo do presente trabalho foi identificar o efeito Big Four sobre a probabilidade de se receber uma opinião modificada do auditor, bem como estimar a probabilidade média de se receber uma opinião modificada.

O estudo, de natureza descritiva, documental e com abordagem quantitativa, analisou dados de 504 (4.720 relatórios) empresas listadas na [B] ${ }^{3}$ no período de 2002 a 2012. Os dados foram coletados no sítio da CVM (Comissão de Valores Mobiliários) e analisados por meio da análise de regressão logística com dados em painel.

Nos últimos anos, as auditorias têm sido muito criticadas por falharem na detecção de erros e fraudes, o que sugere a possibilidade de tendenciosidade dos relatórios emitidos pelas mesmas (KRANACHER, 2008). Isso implica que, conhecer variáveis que possam influenciar na opinião dos auditores, pode contribuir para os órgãos reguladores estabelecerem ações no sentido de se fazer cumprir o que se espera de um serviço de auditoria (IANELLO, 2012). Nesse sentido, analisar o efeito Big Four no tipo de relatório de auditoria emitido no Brasil e sua influência na probabilidade de se receber uma opinião modificada contribuem com: (1) ampliação e consolidação das pesquisas sobre auditoria no Brasil, (2) compreensão das variáveis que afetam na opinião modificada; (3) potencialização do desenvolvimento de pesquisas explicativas na área, (4) identificação de potenciais pontos para melhorias no sistema de regulação. Isso porque, dada a reputação dessas empresas, é possível que seu poder de enforcement quanto à adequação das demonstrações contábeis seja maior. Por outro lado, a concentração do mercado entre essas auditorias pode reduzir a relevância, em função da perspectiva de manutenção do cliente e da fatia de mercado nesse segmento de negócio. Além disso, a reputação do auditor pode: aumentar a visibilidade perante os analistas e a imprensa, aumentar o volume de negócios no mercado de capitais e, ainda, prospectar maior volume de recursos quando da emissão de títulos ou captação junto a instituições de crédito (BARTON, 2005).

O presente artigo foi composto por 05 partes, incluindo esta introdução, em que foram apresentados: o tema, o problema de pesquisa e objetivos a serem alcançados. Na segunda seção, é exposto o referencial teórico, em que são sintetizados os principais conceitos necessários à realização e discussão desta pesquisa. Na terceira seção, apontam-se os procedimentos metodológicos, destacando sua classificação, instrumento de coleta e técnica de análise dos dados, e abordagem do problema. Na quarta seção, apresentaram-se os resultados e sua análise. Na quinta seção, foram demonstradas as considerações finais, limitações e propostas para estudos posteriores. 


\section{Referencial Teórico}

\subsection{Governança corporativa e o papel da auditoria para o Mercado de Crédito e de Capitais}

A Governança Corporativa consiste em todo mecanismo que busca mitigar os conflitos de agência existentes entre as partes envolvidas (agentes, principais e outras partes interessadas - stakeholders), visando alinhar os interesses das partes e maximizar o valor para os acionistas controladores e não controladores (MARQUES, 2016).

Brickley \& Zimmermann (2010) observam que os mecanismos de governança são diversos, tais como: estrutura do conselho, pacote de remuneração, controles internos, auditoria, contratos de dívidas, o ambiente regulatório, os órgãos de classe, dentre outros. Os autores reforçam que, na prática, não existe uma definição única de Governança Corporativa; em geral, quando se trata de uma pesquisa na área, a definição será útil para a delimitação do foco e análise dos dados, mas que, em essência, a busca de um conceito único e geral não deve ser o objetivo.

Apesar disso, existe um esforço mútuo de pesquisadores e órgãos reguladores para estimular a estrutura de governança das empresas brasileiras. Nesse sentido, Marques et al. (2015) afirmam que o IBGC - Instituto Brasileiro de Governança Corporativa - tem incentivado, desde 2001, a adoção de boas práticas de governança. Isso significou a proposição de um sistema ideal de Governança Corporativa que busca privilegiar a interação entre os diversos órgãos deliberativos da companhia e os respectivos órgãos de controle.

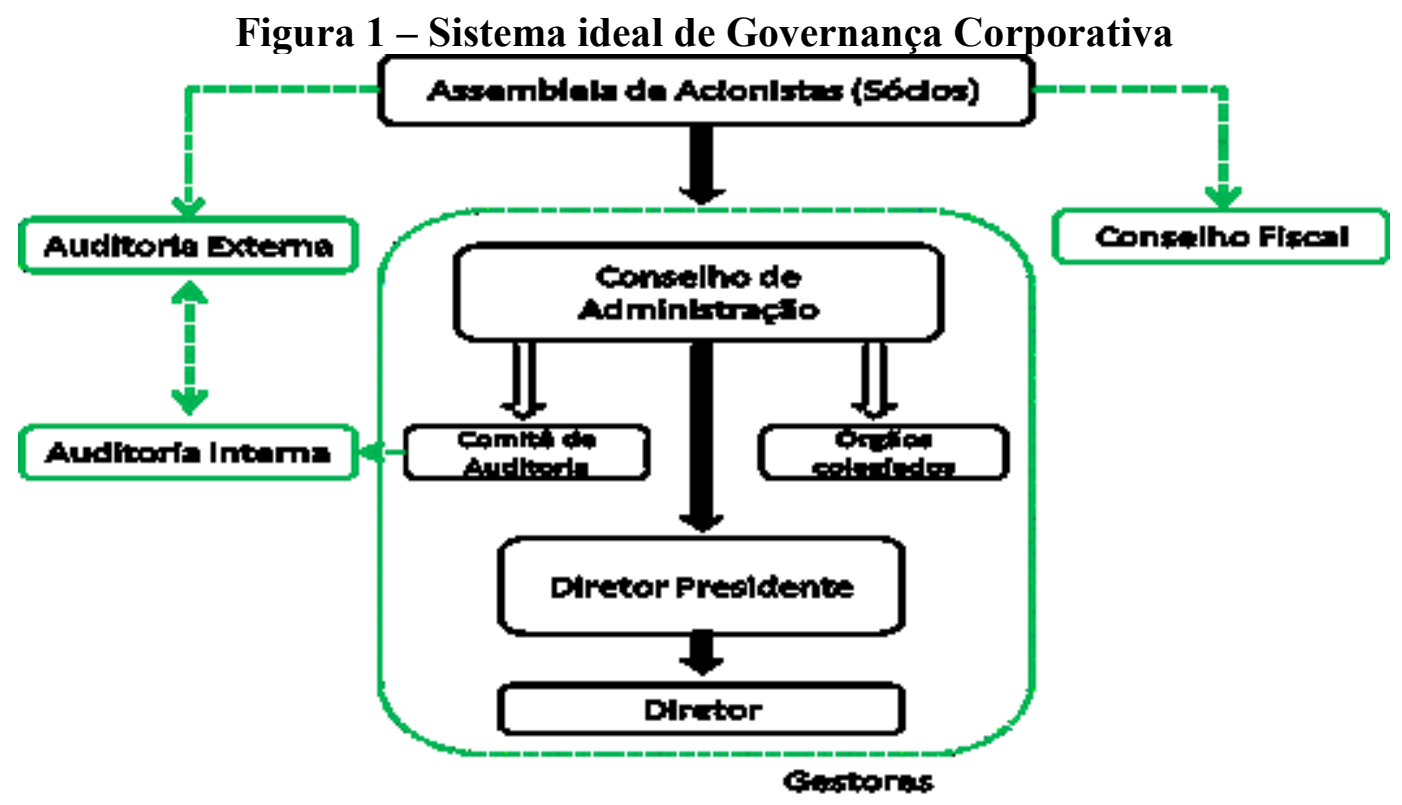

Fonte: Marques et al. (2015)

Desse modo, a Assembleia de Acionistas, como órgão colegiado máximo, através da auditoria externa e do conselho fiscal, monitora o desempenho da companhia que está sob a tutela do Conselho de Administração. O Conselho de Administração, como órgão de gestão colegiado, responde pelo monitoramento dos gestores da companhia por meio do comitê de auditoria e de órgãos colegiados de níveis inferiores e estes, por sua vez, assumem o papel de alinhamento dos interesses dos gestores (presidente e diretoria) com os dos acionistas.

Como se observa (FIG.1), a auditoria adquire papel relevante na estrutura de governança ideal, pois, através da auditoria interna, possibilita que os riscos (operacionais e financeiros) mais 
representativos da companhia sejam mitigados por uma estrutura de controle interno. A preocupação com os controles internos tornou-se evidente após o caso Enron no início de 2001 (DI PIETRA, MCLEAY e RONEN, 2014). Já a auditoria externa certificará quanto à adequação das demonstrações contábeis elaboradas e divulgadas aos provedores de capitais (CAMARGO et al., 2012). Essa certificação ocorre a partir do relatório de auditoria.

Segundo Habib (2013), os relatórios de auditoria classificam-se em modificados e não modificados. De acordo com a Norma Brasileira de Contabilidade - NBC TA 706 - Modificações na Opinião do Auditor Independente, existem três tipos de relatórios de auditoria modificados: (1) com ressalva, (2) opinião adversa e (3) abstenção de opinião. O auditor emitirá uma opinião com ressalva quando as demonstrações contábeis apresentarem distorções individuais (ou conjuntas) não generalizáveis ou quando não conseguir evidências suficientes, mas concluir que possíveis efeitos significativos estejam presentes. A opinião adversa será emitida quando forem encontradas evidências suficientes para se afirmar que distorções individuais (ou em conjunto) generalizadas estão presentes nas demonstrações contábeis. Por fim, a abstenção de opinião ocorrerá quando o auditor não conseguir evidências adequadas e suficientes para emitir uma opinião com ressalva, adversa, bem como, em casos excepcionais, em que o nível de incerteza for tal que não seja possível identificar seu efeito sobre as demonstrações contábeis (CFC, 2012).

Segundo Chen et al. (2016), a opinião modificada do auditor aumenta a percepção de risco por parte dos credores, implicando aumento do custo do capital, menor acesso a fontes de financiamentos e maior exigência de garantias. Além disso, a obtenção de um parecer modificado pode gerar maior prêmio pelo risco por parte dos investidores. De acordo com Lin, Jiang e Xu (2011), a observância de opinião modificada dos auditores no contexto chinês se justifica por dois motivos: (1) os incentivos econômicos ao gerenciamento de resultados e (2) intervenção governamental e de partes relacionadas enfraquecem o papel da informação, estrutura de governança e do relatório de auditoria.

Cullinan et al. (2012) complementam que existe uma tendência de as empresas em anteciparem notícias boas e postergarem as ruins. Segundo esses autores, os relatórios de auditoria modificados estão associados com a tempestividade da divulgação das informações financeiras. Quando a empresa apresenta relatório um relatório não modificado sendo que no ano anterior havia apresentado um relatório modificado, o tempo de divulgação é menor. Por outro lado, quando o relatório do auditor é modificado tende a ser divulgado em período mais longo. Além disso, observou-se que a publicação de notícias ruins teve efeito marginal menor do que os apresentados com modificação positiva.

Verifica-se que a auditoria externa, como instrumento de governança, mostra, ao mercado financeiro, de crédito e de capitais, a certificação de que as informações divulgadas estão ou não adequadas. Essa certificação contribui para o processo de avaliação do desempenho da empresa e dos gestores pelo mercado que considerará como notícia ruim uma opinião modificada e positiva quando o relatório de auditoria for não modificado (XIE, CAI e YE, 2010).

\subsection{Reputação do Auditor e concentração do mercado de auditoria}

A reputação do auditor é um dos principais ativos das firmas desse segmento. Consiste em um constructo em que sua formação decorre de diversos fatores, destacando-se: (1) participação do mercado, (2) capacidade de atrair, treinar e manter a equipe, (3) infraestrutura e tecnologia, (4) poder de enforcement (independência), (5) influência sobre os órgãos de regulação contábil, dentre outros. A reputação do auditor é tão relevante que, em 2001, quando da ocorrência do caso Enron, uma das principais firmas de auditoria, a Artur Andersen, teve suas operações encerradas em decorrência da perda de credibilidade por envolvimento no caso (ASTHANA, BALSAM e KIM, 2009). Dang, Brown $\&$ McCoullough (2011) argumentam que a reputação do auditor tem sido sistematicamente estudada como proxy de qualidade da auditoria e, usualmente, utilizando a classificação entre BigN e Não BigN para operacionlizá-la.

Barton (2005) observa que a reputação do auditor tem papel relevante do mercado, pois, dadas as características da empresa auditada, ela estará mais propensa (ou não) a contratar uma BigN. Argumenta o autor que o relatório de auditoria é uma certificação quanto à adequação das demonstrações contábeis das empresas. Como as BigN apresentam reputação maior no mercado financeiro e de capitais, seus 
clientes, quando trocam de auditor, tendem a fazê-lo para outra grande empresa de auditoria multinacional. Esse comportamento decorre dos custos políticos associados. Por exemplo: empresas que têm maior visibilidade, recomendações e/ou são acompanhadas pelo mercado financeiro, de crédito e de capitais, preocupar-se-ão, em maior nível, com a manutenção de sua posição (e reputação); logo, preferirão as BigN.

Gioelli, Carvalho \& Sampaio (2013) destacam que empresas em processo de abertura de capital têm preocupação com a reputação do auditor. Isso decorre do fato de que o processo visa prospectar recursos de investidores institucionais e individuais para o seu crescimento. Segundo os autores, a contratação de uma empresa de auditoria Big4 é considerada no processo, pois a maior reputação dessas empresas está associada à capacidade de mitigar os problemas de agência, principalmente o gerenciamento de resultados, ocasionando maior confiança nas informações divulgadas.

Entretanto, a despeito de a reputação ser um atributo relevante para as empresas auditadas, os incentivos a tal preferência devem ser contextualizados, pois, isoladamente, eles podem não se materializar. Dang, Brown \& McCullough (2011) verificaram que a reputação do auditor é um aspecto valorizado para sua contratação, já que reforça a reputação da empresa auditada; porém, em termos de Value Relevance, quando a empresa auditada se envolve em casos de fraudes ou erros, a qualidade da informação contábil reduz independentemente de a empresa ser auditada por uma Big4 ou Não Big4. Isso indica que, em condições normais, ser auditado por uma BigN, tende a gerar um prêmio pela reputação do auditor, o que não acontecerá quando a empresa auditada se envolver em alguma irregularidade (erro ou fraude).

Peytcheva \& Gillet (2012) observam que a qualidade do serviço de auditoria é uma função da sua reputação; entretanto, essa reputação sofre efeito de outros fatores, tais como o envolvimento prévio do auditor em casos anteriores de fraude e erro, o que corrobora o apresentado por Dang, Brown \& McCullough (2011). Ou seja, a qualidade do auditor sofre efeito de diversos fatores, entre eles a reputação do auditor. Porém, a reputação tem efeito moderador, pois variáveis que aumentam a percepção de risco por parte do usuário podem ter efeito negativo sobre essa reputação. Por exemplo, o envolvimento prévio da empresa de auditoria em casos de fraudes e/ou erros aumenta o risco percebido por parte do usuário quanto à capacidade de o auditor mitigar falhas nas demonstrações contábeis; logo, sua reputação sofre redução que, por conseguinte, terá menor peso sobre a qualidade da auditoria. Esse movimento, segundo Toth (2014), provoca restrição na demanda dos serviços e, por esse motivo, haverá preocupação permanente dos auditores com a reputação percebida pelo mercado (PIOT, 2005).

O que se deduz, conforme a Figura 2, é que o tipo de auditor e outras características econômicas e institucionais das companhias afetam no tipo de opinião do auditor. Isso implica, por exemplo, que uma empresa com determinado nível de endividamento terá maior ou menor probabilidade de receber uma opinião modificada, dependendo do tipo de auditor que realiza o trabalho de auditoria, dentre outros (PIOT, 2005; BARTON, 2005; DANG, BROWN \& MCCULLOUGH, 2011; GIOELLI, CARVALHO \& SAMPAIO, 2013; TOTH, 2014).

\subsection{Pesquisas anteriores}

Os estudos sobre as determinantes da opinião do auditor buscam, a partir das mais diversas variáveis e teorias, testar hipóteses sobre aquelas que afetam o tipo de opinião do auditor, destacando-se aspectos relativos à independência, risco operacional e às hipóteses decorrentes da teoria da agência, sobretudo, aquelas relativas ao gerenciamento de resultados e escolhas contábeis (BYINGTON e GUTTON, 1991; EISENBERG e MACEY, 2004; BROWN, BEEKES e VERHOEVEN, 2011). 
Figura 2- Determinantes do tipo de opinião do auditor

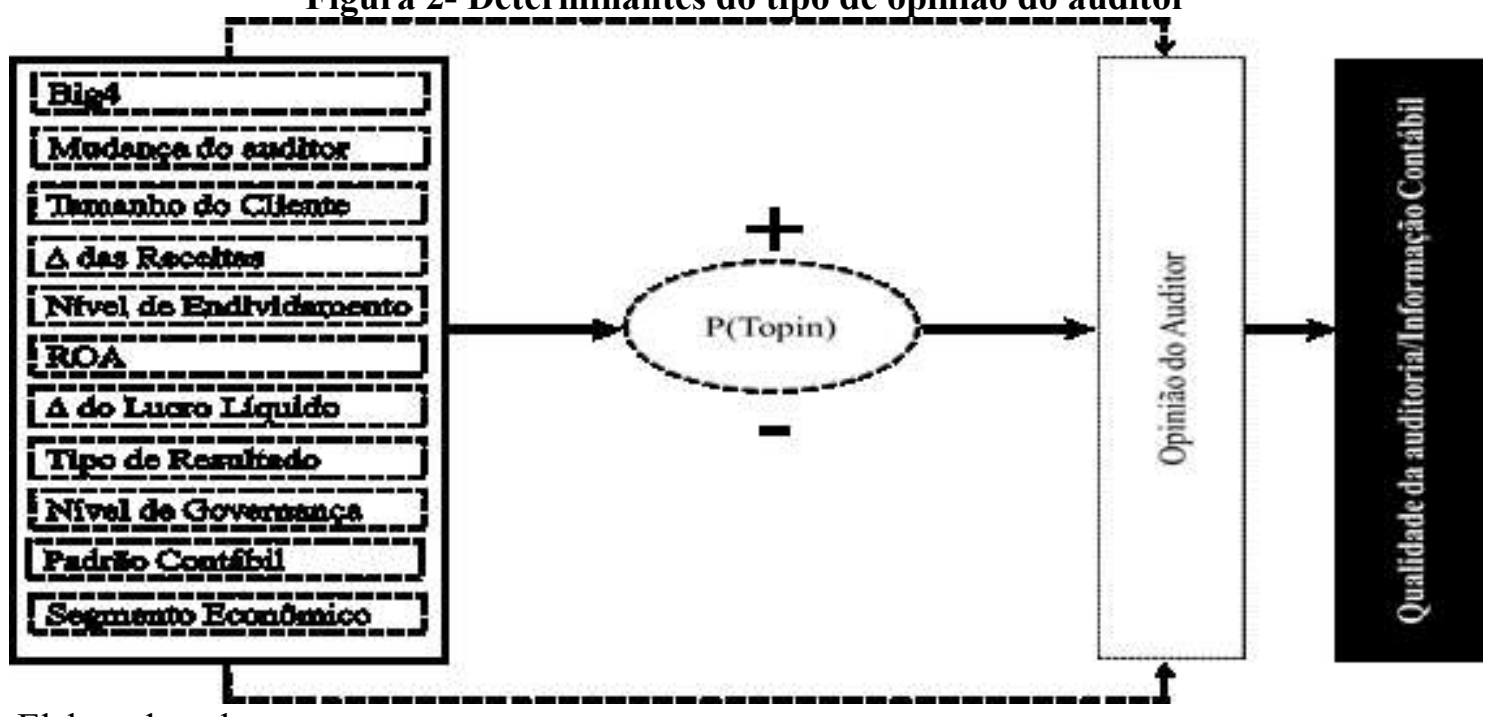

Fonte: Elaborado pelos autores

Um dos aspectos significativos e recorrentemente testados refere-se ao efeito "Big Four" no tipo de opinião emitido e à concentração de mercado entre esses auditores. Almeida e Vasconcelos (2007) destacam que a maioria dos pareceres publicados no período de 2004 foi do tipo sem ressalva $(79,40 \%), 19,20 \%$ com ressalvas e apenas $1 \%$ tratava de pareceres com abstenção de opinião. Além disso, os autores verificaram a concentração de $64,80 \%$ dos pareceres oriundos das chamadas Big Four (Pricewatherhouse, Deloite, Ernest Young e $K P M G)$ e da empresa nacional Trevisan.

Francis e Yu (2009) realizaram um estudo para avaliar o efeito das Big Four na qualidade dos relatórios de auditoria, analisando 6.568 companhias auditadas por 285 empresas de auditoria e seu efeito no gerenciamento de resultados. As evidências confirmaram a expectativa de que as empresas auditadas pelas Big Four apresentaram menores níveis de gerenciamento de resultados e, ainda, os relatórios apontaram maiores probabilidades de reportarem risco de descontinuidade; além disso, diversas variáveis de controle foram utilizadas para se monitorarem outros efeitos, destacando-se: nível de endividamento, mandato da diretoria, risco de falência, volatilidade e crescimento das vendas.

Li, Song e Wong (2008) avaliaram o efeito do tamanho da firma, na opinião dos auditores, no mercado chinês. A amostra foi composta por 2.969 empresas listadas nas Bolsas de Shangai e Shenzhen no período de 2001 a 2003. Os autores observaram como o tamanho do cliente das empresas de auditoria afeta a probabilidade de se emitir um parecer modificado. Evidenciaram que a relação é significativa e negativa, ou seja, quanto maior a empresa de auditoria, menor a probabilidade de se receber um parecer modificado. A explicação para isso pode se relacionar com: (i) maior poder de barganha perante as empresas de auditoria, (ii) menor risco envolvido nestas maiores empresas e (iii) melhor qualidade dos relatórios financeiros emitidos pelas maiores empresas.

Lawrence, Minutti-meza e Zhang (2011) estudaram se existiam diferenças nas proxies de qualidade de auditoria das Big Four e não Big Four. Para realizar o estudo, testaram o nível de gerenciamento de resultados, o custo de capital e a precisão das previsões dos analistas. Eles analisaram 72.600 observações, sendo 59.323 referentes a empresas auditadas pelas Big Four e 13.277 relativas às empresas auditadas pelas não Big Four. Os resultados evidenciaram que as diferenças na qualidade das auditorias realizadas pelas Big Four e não Big Four foram não significativas, entretanto o tamanho do cliente pode influenciar na diferença existente, demandando estudos posteriores para verificação dos achados da pesquisa. 
Perreau e Kida (2011) analisaram a capacidade dos auditores de persuadirem os clientes a aceitarem suas sugestões e/ou posições. Os autores constataram que a forma como as negociações são realizadas, aliadas à reputação do auditor, ao treinamento constante, à imagem percebida e à possibilidade de se modificar o relatório de auditoria, são fatores preponderantes na capacidade de persuasão.

Esses resultados corroboram os achados de Lai (2013). Segundo o autor, as empresas do tipo Big Four apresentam maior propensão de emitirem uma opinião não modificada, em decorrência de maior aversão ao risco; além disso, possuem maior capacidade de suportar a pressão dos clientes e restringir, de forma mais eficaz, o gerenciamento de resultados. Apesar disso, o autor sugere que haja menor concentração do mercado, sob pena e prejuízo à independência e à adequada execução do papel do auditor.

Xie, Cai e Ye (2010) reforçam a influência do poder dos auditores das Big Four sobre as empresas auditadas quando observaram que o pagamento de honorários de auditorias anormais aumenta as chances de se receber uma opinião não modificada apenas em empresas não Big Four, o que sugere melhor capacidade de enforcement e persuasão desse grupo de empresas. Esses resultados são convergentes com os trabalhos de Blandon e Bosch (2012), Blandon e Argiles (2015).

Outros estudos são ressaltados na literatura. A Quadro 1 apresenta um resumo de algumas pesquisas realizadas nos últimos anos e os achados das mesmas. A tabela constitui-se de um recorte de relevantes trabalhos publicados em journals clássicos no campo da contabilidade nos últimos anos, destacando-se que outras análises tão ou quão relevantes podem existir. Além disso, outras pesquisas serão utilizadas para fundamentar as variáveis, modelos e hipóteses desenvolvidas. 
Quadro 1 - Síntese de pesquisas anteriores sobre auditoria publicadas nos principais Journals e Base de Dados Científicas nos últimos anos

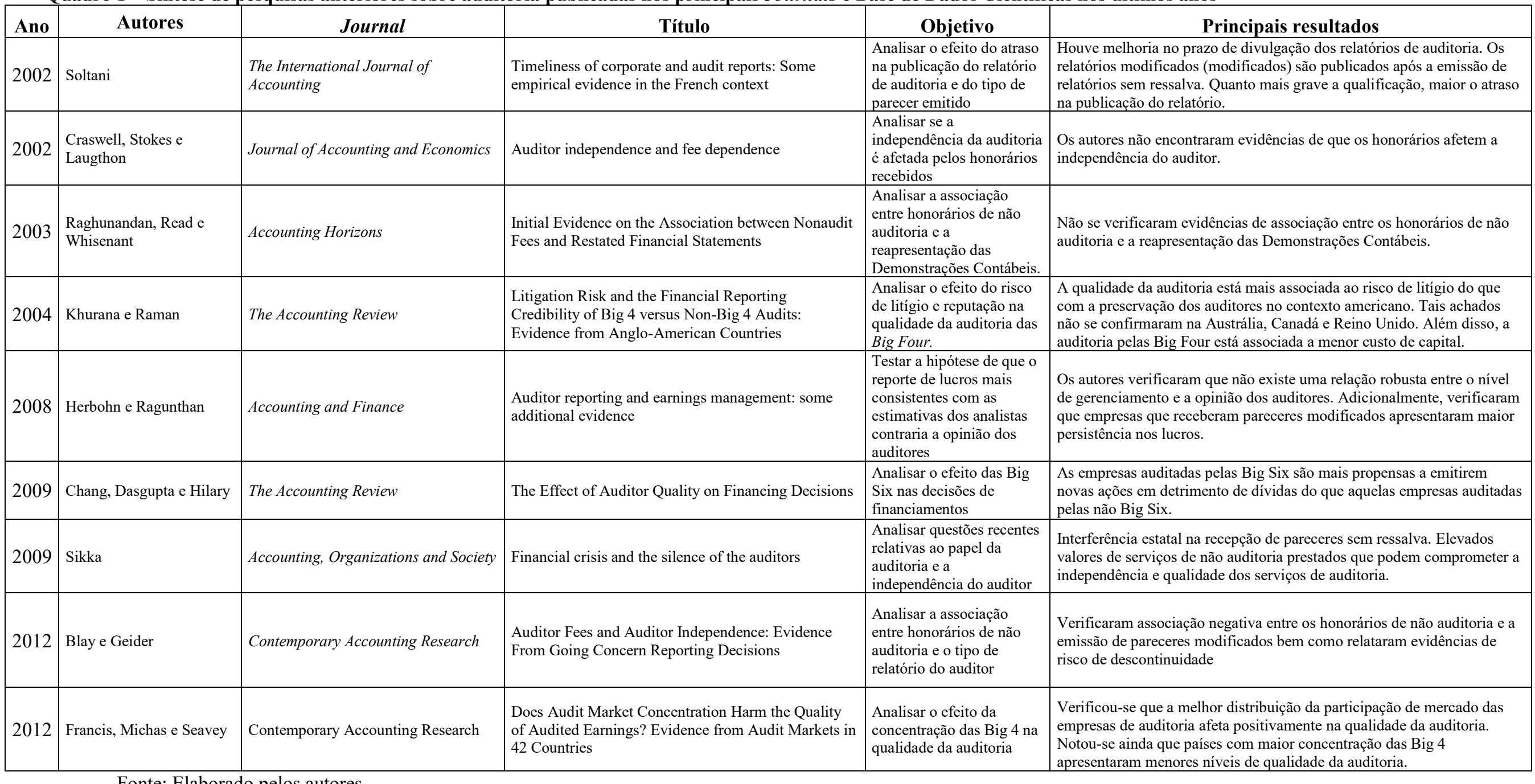

Fonte: Elaborado pelos autores apresentaram menores níveis de qualidade da auditoria. 


\section{Procedimentos Metodológicos}

O presente estudo classificou-se como descritivo, documental e com abordagem quantitativa. Cooper \& Schindler (2003) afirmam que as pesquisas descritivas são aquelas em que: (i) se descrevem características de uma amostra (ou população), (ii) se estimam proporções ou probabilidade de determinados eventos, (iii) se analisam associações entre variáveis e (iv) se verifica a relação de causalidade estatística entre variáveis. Quanto aos procedimentos, tratase de uma pesquisa documental em que as fontes dos dados são documentos, sendo as evidências obtidas decorrentes de eventos ocorridos, considerando-se uma pesquisa ex post facto (MALHOTRA, 2006). Utilizaram-se, na investigação, dados das demonstrações contábeis e os respectivos relatórios de auditorias anuais publicados na CVM - Comissão de Valores Mobiliários - por empresas que negociam ações na $[\mathrm{B}]^{3}$ no período de 2002 a 2012. Por fim, Cooper \& Schindler (2003) afirmam que a abordagem quantitativa se utiliza da matemática e estatística para se analisarem os dados e responder ao problema, geralmente, testando hipóteses ou modelos. A estatística descritiva e análise de regressão logística com utilização de dados em painel foram usadas como técnicas de análise (WOOLDRIDGE, 2010). A amostra foi composta por empresas de capital aberto, excluindo 10 empresas que não apresentavam informações completas disponíveis no sítio da CVM e outras 04 não foram classificadas quanto ao setor econômico conforme a BMF \& Bovespa e, por isso, não foram consideradas na amostra. Para a estimação do modelo, trabalhou-se com uma amostra de 494 empresas das 504 inicialmente coletadas entre as 518 listadas até 31/12/2012. As exclusões ocorreram para correção/mitigação de problemas econométricos.

\subsection{Hipótese, Modelo e Variáveis}

Os fatores que afetam no tipo de opinião do auditor são diversos (SERRA e RODRIGUES, 2012; BLAY e GLEIDER, 2012; GAGANIS, PASIOURAS e SPATHIS, 2013; HABIB, 2013). Fatores associados à estrutura de governança, ao ambiente de negócios e características econômicas das firmas estão relacionados ao maior potencial de identificação de irregularidades e falhas (SMAILI e LABELLE, 2016); logo, a probabilidade de obtenção de uma opinião modificada será uma função desses fatores. Abughazaleh, O'Connel e Princen (2015) observam que a qualidade da auditoria é uma função de múltiplos fatores, mas o tamanho, o ambiente legal e o tipo de auditor podem assumir papel preponderante. Essa perspectiva é coerente na medida em que empresas de maior tamanho demandam uma estrutura de governança mais robusta (SMAILI e LABELLE, 2016); além disso, o ambiente legal pode fortalecer ou enfraquecer os mecanismos de governança uma vez que os agentes terão incentivos (ou restrições) econômicos para agirem oportunisticamente (MARQUES, 2016).

Por sua vez, a qualidade da auditoria, muitas vezes medida pelo nível de independência do auditor, está associada à sua reputação (ASTHANA, BALSAM e KRISHNAN, 2010). Chen et al., (2016) destacam que uma das proxies utilizadas para se avaliar a independência do auditor é o volume de relatórios modificados emitidos; por outro lado, essa mesma métrica é um parâmetro de qualidade da informação em que, quanto menor o percentual de opiniões modificadas, maior será a qualidade da informação contábil. Entretanto, essa menor emissão pode ser um dos efeitos adversos da competitividade no setor, pois, em função do tamanho da entidade auditada e dos respectivos honorários recebidos, o auditor pode exercer sua preferência por manter o cliente em detrimento da emissão de opinião modificada (HABIB, 2013).

Apesar disso, existe a preocupação permanente por parte dos auditores quanto à sua reputação (PARACINI, MALSCH e PAILLÉ, 2014; TOTH, 2014). Isso porque a reputação do

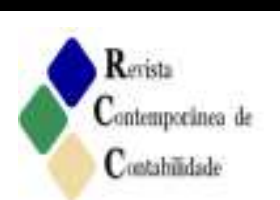


auditor pode reduzir as incertezas dos diversos usuários, gerando incentivos econômicos para sua contratação futura; logo, estarão propensos a buscarem mecanismos que mitiguem o risco associado à atividade de auditoria para manterem suas posições no mercado (MACCRAKEN, 2003; AUTORE, BILLINGSLEY e SCHENELLER, 2009; CHEN et al., 2016).

Chen et al. (2016) afirmam que as Big Four têm maior grau de independência do cliente. MacCraken (2003) assegura que a reputação do auditor é o seu principal ativo. Essa preocupação com a reputação é convergente com o comportamento observado das Big Four em processos abertos contra eles pela Comissão de Valores Mobiliários - CVM. Segundo Veloso et al. (2015), as firmas de auditoria Big Four tendem a procurar fazer acordos para que se extingam os processos abertos contra elas. Isso implica que a hipótese principal do presente estudo foi:

\section{$H_{1}$ : As empresas auditadas pelas Big Four têm maior propensão a receberem um relatório} modificado.

Por outro lado, Cao et al. (2015) complementam que empresas de maior tamanho e visibilidade também esperam que uma opinião não modificada seja emitida e, nesse sentido, envidarão esforços para mitigarem os riscos de fraudes e erros, bem como estarão mais propensas a realizarem ajustes necessários a fim de eliminarem distorções que ensejam a emissão de relatório modificado. Além disso, micro e macro fatores institucionais podem afetar no tipo de opinião emitida pelo auditor. Camargo et al. (2012) observam ainda que a literatura apresenta, pelo menos, 50 variáveis possíveis de afetarem o tipo de opinião do auditor. Em seu estudo, o autor agrupou-os em 16 fatores. Verifica-se, a partir desses elementos, que se referem: ao tamanho da firma (ativo, receitas e lucro), nível de endividamento (liquidez, endividamento), nível de desempenho (Índices de Rentabilidade e Giro), nível de qualidade da auditoria (tipo de auditor, honorários de auditoria, serviços de não auditoria), estrutura de governança (nível de governança, comitê de auditoria) e estrutura de mercado (segmentos econômicos em que atuam). Alicerçado na hipótese apresentada anteriormente e fundamentado na literatura consultada, propôs-se o seguinte modelo (Equação 1):

$\operatorname{Prob}($ TOpin $)=\beta_{0}+D_{1}$ BigFour $+\beta_{1}$ ParEnf $+\beta_{2}$ Tam $+\beta_{3} \Delta$ Rec $+\beta_{4}$ NivEnd $+\beta_{5}$ ROA + $\beta_{6} \Delta \mathrm{LL}+D_{2}$ TipRes $+D_{3}$ NivGov $+D_{4}$ SOX $+D_{5}$ IFRS Parcial $+D_{6}$ IFRS Full $+D_{7}$ SegEcon $+D_{8}$ Ano

A operacionalização da variável de interesse e as de controle, bem como os sinais esperados e estudos que analisaram a questão direta ou indiretamente e fundamentam as relações esperadas estão apresentados na Quadro 2.

\subsection{Técnica de Análise dos Dados}

No presente trabalho, buscou-se testar a hipótese de que ser auditado por uma Big Four reduz as chances de se receber uma opinião modificada (TOpin): $H_{0_{1}}$ : BigFour $\rightarrow$ TOpin, $H_{1_{1}}:$ BigFour $\neg \rightarrow$ TOpin . Complementarmente, analisou-se o efeito marginal das variáveis utilizadas. Espera-se que exista uma relação negativa e significativa na probabilidade de as empresas auditadas por Big Four receberem pareceres modificados (Camargo et al., 2012). As variáveis testadas foram as apresentadas na Quadro 1 e foram testadas do modelo Logit conforme a Equação 1. 
Quadro 2 - Relação de hipóteses para as variáveis de controle do modelo

\begin{tabular}{|c|c|c|c|}
\hline Variável & Descrição & $\begin{array}{c}\text { Sinal } \\
\text { Esperado }\end{array}$ & Pesquisas anteriores \\
\hline \multicolumn{4}{|c|}{ Explicada } \\
\hline TOpin & $\begin{array}{l}\text { Variável dummy que assume valor } 1 \text { quando a } \\
\text { opinião do auditor for modificada (Com Ressalva, } \\
\text { Adverso ou Abstenção de Opinião) e zero quando } \\
\text { não. }\end{array}$ & $(+)$ & $\begin{array}{l}\text { Serra \& Rodriguez (2013), Habib (2016), } \\
\text { Marques (2016) }\end{array}$ \\
\hline \multicolumn{4}{|c|}{ Explicativa (Interesse) } \\
\hline Big Four & $\begin{array}{l}\text { Variável dummy que assume valor } 1 \text { quando o } \\
\text { auditor for uma Big Four (KPMG, Deloitte, Ernest } \\
\text { \& Young e Pricewaterhouse) e zero quando não. }\end{array}$ & $(+)$ & 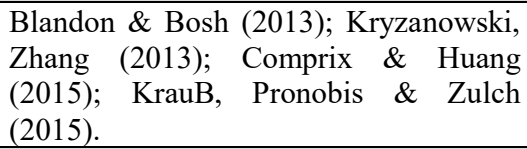 \\
\hline \multicolumn{4}{|c|}{ Explicativas (Controle) } \\
\hline MudAudit & $\begin{array}{l}\text { Variável dummy que assume valor } 1 \text { quando } \\
\text { houver mudança de auditor e zero quando não. }\end{array}$ & $(+)$ & $\begin{array}{l}\text { McHuth III e Polinski, (2012); Azevedo } \\
\text { \& Costa, (2012); Herz (2014); Ebrahin } \\
\text { (2013); Heliodoro, Carreira \& Lopes } \\
\text { (2016) }\end{array}$ \\
\hline ParEnf & $\begin{array}{l}\text { Quantidade de Paragáfos de Ênfases do relatório } \\
\text { de auditoria da iésima empresa no ano t. }\end{array}$ & $(+)$ & $\begin{array}{l}\text { Santos et al. (2009); Camargos (2012); } \\
\text { Marques (2016) }\end{array}$ \\
\hline Tam & $\begin{array}{l}\text { Logaritmo natural do total dos ativos da iésima } \\
\text { empresa no momento t. }\end{array}$ & $(-)$ & $\begin{array}{l}\text { Farinha \& Viana (2009), Habib (2013); } \\
\text { Foster \& Shatri (2016); Chen et al. } \\
(2016)\end{array}$ \\
\hline$\Delta \mathrm{Rec}$ & $\begin{array}{l}\text { Receitas Líquidas do ano } t \text { divididas pelas receitas } \\
\text { líquidas do ano } t-1 \text {, subtraídas de } 1 \text {. }\end{array}$ & $(+)$ & $\begin{array}{l}\text { Bonne, Khurana \& Raman (2012); Chen } \\
\text { et al. (2013); Suarez et al. (2013); } \\
\text { George \& Lin (2014) }\end{array}$ \\
\hline NivEnd & Total do passivo dividido pelo total do ativo. & $(+)$ & $\begin{array}{l}\text { Lennox e Li (2014); Comprix \& Huang } \\
\text { (2015); Chen } \text { et al. (2016). }\end{array}$ \\
\hline ROA & Lucro líquido dividido pelo total do ativo. & $(-)$ & $\begin{array}{l}\text { Suarez et al. (2012); Habib (2013); Toth } \\
\text { (2014); Foster \& Shastri (2016). }\end{array}$ \\
\hline$\Delta \mathrm{LL}$ & $\begin{array}{l}\text { Lucro líquido do ano } t \text { dividido pelo lucro líquido } \\
\text { do ano } t-1 \text {, subtraídos de } 1 \text {. }\end{array}$ & $(+)$ & $\begin{array}{l}\text { Suarez et al. (2013); Habib (2013); Toth } \\
\text { (2014); Foster \& Shastri (2016). }\end{array}$ \\
\hline TipRes & $\begin{array}{l}\text { Variável dummy que assume valor } 1 \text { quando a } \\
\text { empresa apresentar prejuízo e zero quando } \\
\text { apresentar lucro. }\end{array}$ & $(+)$ & $\begin{array}{l}\text { Suarez et al. (2013); Habib (2013); Toth } \\
\text { (2014); Foster \& Shastri (2016). }\end{array}$ \\
\hline NivGov & $\begin{array}{l}\text { Variável dummy que assume valor } 1 \text { quando a } \\
\text { empresa estiver em um dos níveis diferenciados de } \\
\text { governança e zero quando estiver no tradicional. }\end{array}$ & $(-)$ & $\begin{array}{l}\text { DeFond \& Lennox (2011); Scott \& Gist } \\
\text { (2013); Pei \& Hamill (2013) }\end{array}$ \\
\hline Pré-IFRS & $\begin{array}{l}\text { Variável dummy que assume valor } 1 \text { para os anos } \\
\text { anteriores à adoção do IFRS parcial (2005-2007) e } \\
\text { zero para os demais. }\end{array}$ & $(+)$ & $\begin{array}{l}\text { Tsipouridou \& Spathis (2012); Serra \& } \\
\text { Rodriguez (2013); DeFond \& Zhang } \\
\text { (2014) }\end{array}$ \\
\hline IFRS Parcial & $\begin{array}{l}\text { Variável dummy que assume valor } 1 \text { para o ano de } \\
\text { adoção parcial do IFRS (2008) e zero para os } \\
\text { demais. }\end{array}$ & $(+)$ & $\begin{array}{l}\text { Tsipouridou \& Spathis (2012); Serra \& } \\
\text { Rodriguez (2013); DeFond \& Zhang } \\
\text { (2014) }\end{array}$ \\
\hline IFRS Full & $\begin{array}{l}\text { Variável dummy que assume valor } 1 \text { para o ano de } \\
\text { adoção integral do IFRS (2010) e zero para os } \\
\text { demais. }\end{array}$ & $(+)$ & $\begin{array}{l}\text { Tsipouridou \& Spathis } \quad \text { (2012); } \\
\text { Tsipouridou \& Spathis (2014) }\end{array}$ \\
\hline SOX & $\begin{array}{l}\text { Variável dummy que assume valor } 1 \text { para o ano de } \\
\text { adoção da SOX (2002) e zero para os demais. }\end{array}$ & $(+)$ & $\begin{array}{l}\text { Zhang (2007); Habibs (2013); Pei \& } \\
\text { Hamill (2013); DeFond \& Zhang (2014) }\end{array}$ \\
\hline SegEcon $_{i j}$ & $\begin{array}{l}\text { Variável dummy que assume valor } 1 \text { para iésimo } \\
\text { segmento econômico da empresa j e zero para os } \\
\text { demais. }\end{array}$ & $(+/-)$ & $\begin{array}{l}\text { Habibs (2013); Serra \& Rodriguez } \\
\text { (2013); DeFond \& Zhang (2014) }\end{array}$ \\
\hline $\mathrm{Ano}_{t}$ & $\begin{array}{l}\text { Variável dummy que assume valor } 1 \text { para o ano t e } \\
\text { zero para os demais. }\end{array}$ & $(+/-)$ & $\begin{array}{l}\text { Habibs (2013); Serra \& Rodriguez } \\
\text { (2013); DeFond \& Zhang (2014) }\end{array}$ \\
\hline
\end{tabular}

Fonte: Elaborado pelos autores 
Para operacionalização da regressão logística foram adotados os seguintes procedimentos: (i) transformação da variável dependente em dicotômica para identificação dos grupos; (ii) análise da correlação entre as variáveis de estudo; (iii) as variáveis independentes foram inseridas no modelo logit para estimação da capacidade de definição da razão de chances; (iv) gerou-se o efeito marginal das variáveis do modelo logit, (v) matriz de classificação para teste de validação do modelo; (vi) geração e interpretação da curva ROC; (vii) cálculo do odds ratio para análise das probabilidade; (viii) a amostra foi subdividida em duas janelas sendo rodadas três grupos de regressões logísticas para capturar o efeito entre os modelos e identificar o efeito que a adoção do IFRS provocou no estudo; (iv) a análise incremental entre a capacidade de explicação das variáveis de estudos foi aplicada para capturar a mudança de efeito entre as variáveis. Os procedimentos adotados foram orientados por Hosmer e Lemeshow (2000), Gujarati (2006) e Wooldridge (2010) e os testes quanto aos pressupostos econométricos foram adotados e quando necessário e possível foram adotadas as correções aplicáveis.

\section{Análise de Dados e Discussão dos Resultados}

\subsection{Conteúdos e Características dos Relatórios}

Inicialmente, analisaram-se as características dos relatórios emitidos no período estudado. Observou-se que foram produzidos 4.720 relatórios para uma quantidade de 315 a 494 empresas participantes da [B] $]^{3}$. Destes, 90,32\% foram do tipo Não modificado ou Sem Ressalva. Outros $9,68 \%, 457$ relatórios emitidos, foram do tipo modificado, sendo que 92,56\% destes foram Com Ressalvas conforme se verifica na Tabela 1.

Tabela 1 - Tipos de relatórios emitidos por segmento econômico no período de 2002-2012

\begin{tabular}{|c|c|c|c|c|c|c|c|c|c|}
\hline $\begin{array}{l}\text { Segmentos } \\
\text { Econômicos }\end{array}$ & SR & $\mathbf{C R}$ & AD & NO & $\begin{array}{l}\text { Segmentos } \\
\text { Econômicos }\end{array}$ & SR & CR & AD & NO \\
\hline Bens Industriais & 331 & 37 & 0 & 11 & $\begin{array}{l}\text { Construção e } \\
\text { Transportes }\end{array}$ & 388 & 29 & 0 & 0 \\
\hline $\begin{array}{l}\text { Construção e } \\
\text { Transportes }\end{array}$ & 564 & 48 & 0 & 4 & $\begin{array}{l}\text { Petróleo, Gás e } \\
\text { Biocombustíveis }\end{array}$ & 47 & 2 & 0 & 0 \\
\hline $\begin{array}{l}\text { Consumo } \\
\text { Cíclico }\end{array}$ & 531 & 77 & 0 & 1 & $\begin{array}{l}\text { Tecnologia da } \\
\text { Informação }\end{array}$ & 74 & 3 & 0 & 0 \\
\hline $\begin{array}{l}\text { Consumo Não } \\
\text { Cíclico }\end{array}$ & 280 & 41 & 1 & 7 & Telecomunicações & 98 & 9 & 0 & 0 \\
\hline $\begin{array}{l}\text { Financeiro e } \\
\text { Outros }\end{array}$ & 1.262 & 109 & 0 & 3 & Utilidade Pública & 688 & 68 & 0 & 7 \\
\hline \multicolumn{6}{|c|}{ Total de relatório por tipo de opinião do auditor } & 4.263 & 423 & 1 & 33 \\
\hline \multicolumn{6}{|c|}{ Percentual dos relatórios por tipo de opinião do auditor } & $90,32 \%$ & $8,96 \%$ & $0,02 \%$ & $0,70 \%$ \\
\hline
\end{tabular}

SR - Sem Ressalva CR - Com Ressalva AD - Adverso NO - Negativa de Opinião

Fonte: Dados da pesquisa

Verificou-se que o setor financeiro foi o que apresentou a maior quantidade de relatórios emitidos (1.374) a, aproximadamente, 125 instituições. Destes, 8,15\% foram do tipo modificado (109 Com Ressalvas e 03 com Negativa de Opinião). Outros três segmentos econômicos (Construção e Transporte, Consumo Cíclico e Utilidade Pública) representaram juntos $42,12 \%$ do total de relatórios expedidos (1988). Destes, $10,31 \%$ foram do tipo modificado (193 Com Ressalva, 12 Com Negativa de Opinião). Dentre os setores que apresentaram maior percentual de relatórios modificados, destacou-se o de Consumo Não Cíclico, com um total de 14,89\%; ademais, esse segmento foi o único que mostrou um relatório adverso. No sentido oposto, foi o setor que expôs menor proporção de relatórios modificados de Tecnologia da Informação, totalizando 3,90\% do total de relatórios despachados para essa 
esfera. As características setoriais podem apresentar indícios de possíveis influências do setor na propensão de se receber uma opinião modificada.

Quando analisado o total de relatórios emitidos por empresa de auditoria (Gráfico 1), observou-se que a maioria foi emitida pelas Big Four (61\%). Outras quatro grandes empresas de auditoria nacionais responderam por $16 \%$ do total de relatórios emitidos e $22 \%$, o restante, por aproximadamente 129 empresas de auditoria. Esses resultados evidenciam a concentração das Big Four e de quatro grandes empresas nacionais, que juntas responderam por $77 \%$ do total de relatórios emitidos, enquanto as demais empresas de auditoria, em média, emitiram apenas 08 relatórios ao longo de 2002-2012, o que implica em menos de 01 relatório por ano, em média, para cada uma dessas demais empresas. Tal situação é inadequada, pois pode enfraquecer a independência dos auditores em relação aos seus clientes (DANTAS et al., 2011; BLAY E GEIDER, 2012; FRANCIS, MICHAS E SEAVEY, 2012).

\section{Gráfico 1 - Total de relatórios emitidos pelas empresas de auditoria no período de 2002-} 2012

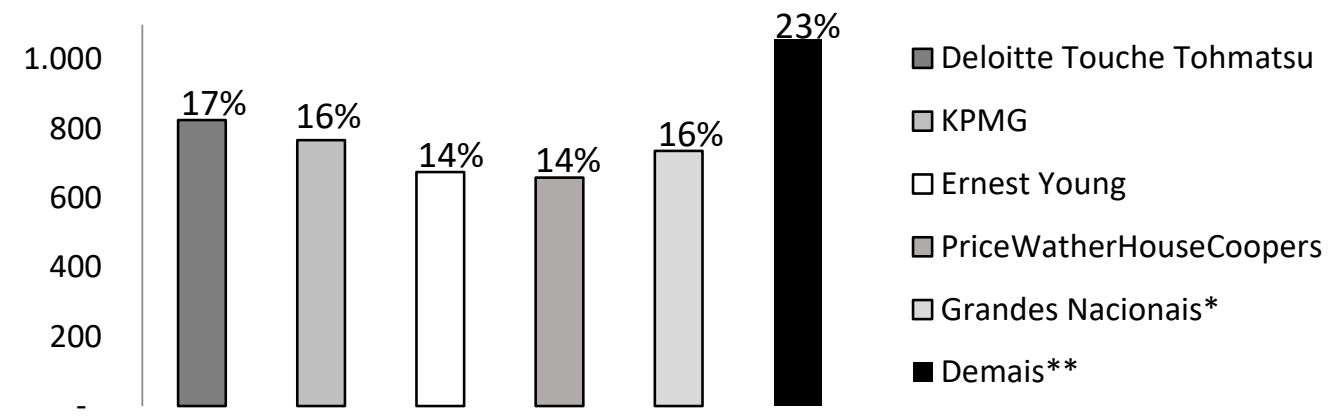

*BDO Trevisan, Performance, BKR e Boucinhas

** Outras 129 empresas

Fonte: Dados da pesquisa

Estudos anteriores no contexto nacional e estrangeiro têm evidenciado essa concentração das Big Four como empresas contratadas para auditar as demonstrações contábeis, atribuindolhes uma opinião que preferencialmente seja do tipo Sem Ressalva. Essa estrutura, que representa aproximadamente a estrutura de mercado das grandes empresas, sugere a necessidade de revisão e crítica sobre o real ganho de qualidade por se contratar uma Big Four em detrimento de outras empresas, pois a estrutura atual pode sugerir quebra ou redução da independência dos auditores dessas grandes empresas de auditoria conforme observam Chen, Srinidi e Su (2014).

Quando analisada a evolução em termos percentuais dos relatórios emitidos por empresas, algumas questões ficam evidentes e, dentre elas, a concentração. Primeiro porque, no período de 2002 a 2007, as Big Four responderam por aproximadamente 50\% dos relatórios emitidos, o que ainda se considera uma concentração elevada nessas empresas, por se tratar de apenas 04 . Entretanto, de 2008 a 2010, período de adoção parcial e integral das Normas Internacionais de Contabilidade, verificou-se o crescimento acentuado das empresas do tipo Big Four, pois, em 2010 , chegaram a responder por $75 \%$ do total de relatórios emitidos às empresas participantes da amostra. No sentido oposto, as demais empresas reduziram sua participação, chegando a $25 \%$ em 2010 e $29 \%$ nos anos subsequentes. Essa situação foi observada em outros mercados e períodos e reforça as críticas acerca da fidedignidade de opinião dos auditores e seus efeitos (HE e CHIANG, 2013). 
Gráfico 2 - Percentuais dos tipos de relatórios emitidos no período de 2002-2012

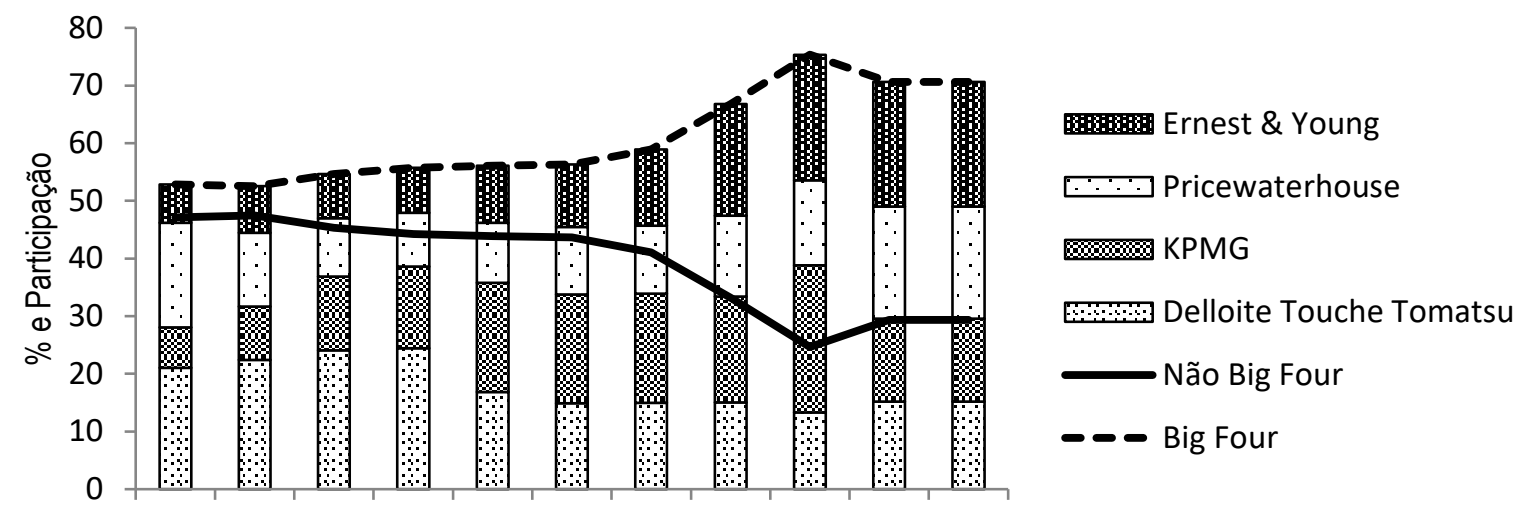

2.002 2.0032.0042.005 2.0062.0072.008 2.0092.0102.0112.012

Fonte: Dados da pesquisa

Analisando-se as evoluções percentuais por empresa do tipo Big Four, constatou-se que Delloite, KPMG e PriceWatherhouse apresentaram um comportamento semelhante à média de crescimento da quantidade de relatórios emitidos pelas Big Four (Gráfico 2). Destaca-se que, no período de adoção das IFRS, todas elas aumentaram a quantidade de relatórios expedidos às empresas participantes da [B] ${ }^{3}$, reforçando o poder da reputação das Big Four.

Por já auditarem empresas sujeitas à adoção das Normas Internacionais em outros mercados, as Big Four possuem conhecimento prévio acerca dos critérios de mensuração, reconhecimento e divulgação das normas adotadas. Apesar da predominância das maiores empresas e suas reputações, algumas evidências indicam que não existem diferenças significativas na qualidade da auditoria de uma Big Four e uma Não Big Four (LAWRENCE e MINUTT-MEZA, 2011).

Posteriormente, na Gráico 3, analisaram-se as taxas de variações dos tipos de relatórios (Não Modificados, Modificados e suas variações - Adverso, Com Ressalvas, Com Negativa de Opinião). Observou-se que os relatórios do tipo Não modificados não sofreram variações elevadas, o que sustenta a quantidade da tendência de emissão de relatórios desse tipo para as empresas participantes da $[\mathrm{B}]^{3}$.

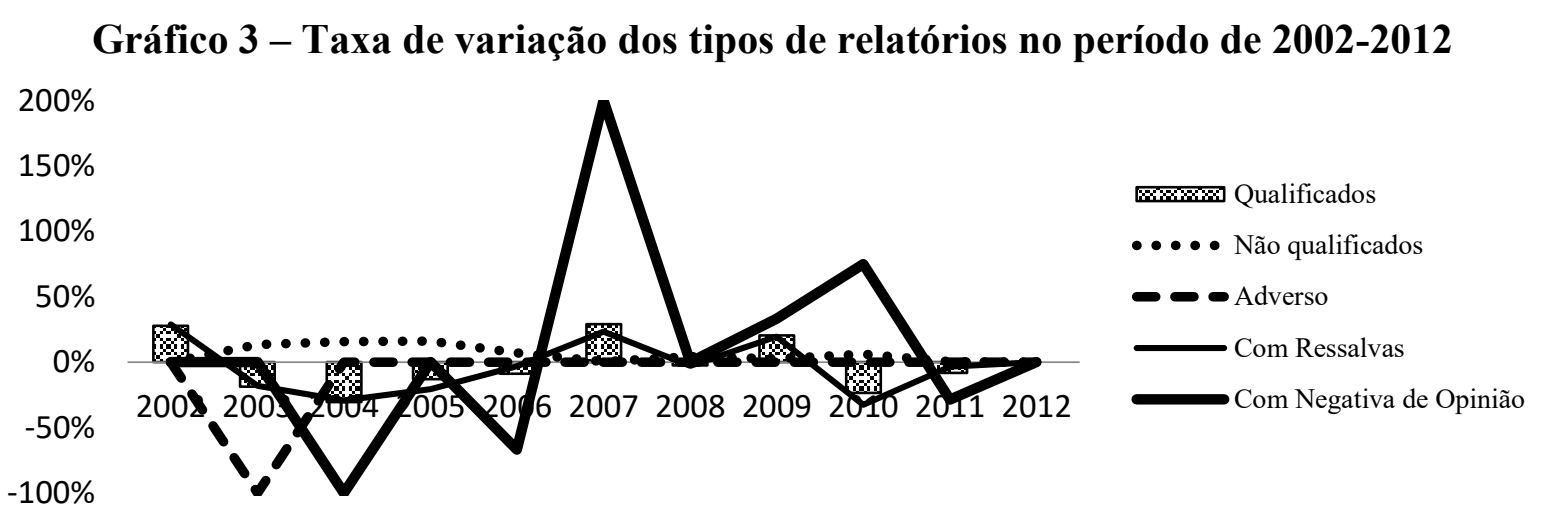

Fonte: Dados da pesquisa

Já quanto aos relatórios do tipo modificados, verificou-se que, no período de 2002 a 2005 , houve tendência de queda, retornando ao crescimento a partir de 2006, sofrendo o maior aumento no ano de 2007, ano da pré-adoção das IFRS. Desde então, as taxas de variações 
apresentaram um comportamento sazonal, sugerindo, entretanto, uma tendência de estacionariedade na quantidade de relatórios desse tipo a partir de 2011.

Dentre os modificados, os Com Ressalvas representaram quase a totalidade como mencionado anteriormente, observando-se taxa de variação semelhante para este tipo de relatório. Para os demais, Adverso e Com Negativa de Opinião, percebeu-se que os primeiros sofreram redução entre 2002 e 2003, com aumento no ano de 2004. A partir daí, não houve variação no número de relatórios desse tipo emitidos às empresas participantes da amostra. Os relatórios com Negativa de Opinião mostraram sazonalidade ao longo do período, destacando crescimento no ano de 2007 e 2010, respectivamente, no ano pré-adoção inicial das IFRS Parciais e no ano da adoção integral desse padrão de normas, sugerindo maior percepção e risco de auditoria pelos auditores. Os resultados convergem para os achados de estudos anteriores que apontaram comportamento homogêneo no total de relatórios modificados, notando-se, entretanto, uma sensibilidade pequena em decorrência do aumento do número de empresas participantes do mercado de capitais (DANTAS et al., 2011; LAI, 2013; ALMEIDA e ALMEIDA, 2009).

\subsection{Determinantes da Opinião do Auditor}

Posteriormente, considerando o objetivo geral do estudo, analisaram-se os fatores determinantes da probabilidade de chances de uma empresa participante da $[\mathrm{B}]^{3}$ receber um relatório modificado (TAB.2). Para a respectiva análise, separaram-se os dados em três períodos: um período integral (2002-2012), um período de 2002 a 2007, pré-adoção das IFRS e outro período pós-adoção das IFRS (de 2008-2012). Inicialmente, verificou-se que, em todos os modelos testados, rejeitou-se a hipótese de que todas as variáveis explicativas utilizadas eram estatisticamente iguais a zero, considerando o nível de significância de 1\%. Além disso, observou-se, a partir do Pseudo $\mathrm{R}^{2}$ (de McFadden), que, em média, 12\% da probabilidade de se receber um parecer modificado decorre das variáveis testadas. Esse percentual aumentou para $13,22 \%$ no período pós-adoção das IFRS.

Quanto à adequação do modelo, notou-se que a estatística $x^{2}$ do Teste Hosmer-Lemeshow, nos três modelos testados, não pode rejeitar a hipótese de que há associação entre os valores previstos e os observados, já que os p-valores foram superiores a 0,90, 0,43 e 0,95, respectivamente, evidenciando o bom ajuste dos modelos, sobretudo, aquele do período pósadoção das IFRS. Adicionalmente, constatou-se que a capacidade de classificação do modelo foi elevada (entre $80 \%$ e $92 \%$ ). De acordo com os parâmetros definidos por Fávero (2015), trata-se de uma medida de adequação do modelo. Já a área de abrangência da curva ROC Receiver Operating Characteristic - ficou entre $74 \%$ e $76 \%$, sugerindo uma capacidade de discriminação aceitável. Segundo Hosmer e Lemeshow (2000), a regra para avaliação da qualidade discriminatória do modelo é considerada aceitável entre 0,70 e 0,80 ; excelente entre 0,8 e 0,90 ; e excepcional quando acima de 0,90 .

No que se refere às determinantes dos tipos de relatórios recebidos pelas empresas brasileiras participantes da [B] $]^{3}$, observou-se, no período de 2002 a 2012, que ser auditado por uma Big Four reduz em 4,03\% a probabilidade de se receber uma opinião modificada, ocorrendo o mesmo com as variáveis: (1) $\Delta$ Receitas $(0,27 \%)$, (2) ROA, (3) $\Delta$ Resultado e (4) Nível de Governança (6,08\%); entretanto, o efeito marginal Retorno sobre os Ativos e $\Delta$ Resultado foi muito pequeno (próximo a 0), apesar de serem estatisticamente significativos. Complementarmente, os setores: Financeiro e Outros e Tecnologia da Informação apresentaram um efeito significativo, reduzindo em $3,24 \%$ e 4,12\% a probabilidade de se receber uma opinião modificada. Entre as variáveis que aumentam essa chance, destacaram-se: (i) Quantidade de 
Parágrafos de ênfase, (ii) Tamanho, (iii) Divulgação de Prejuízo, (iv) Adoção Parcial IFRS, (v) SOX. Neste grupo, o único setor que mostrou efeito positivo foi o de Consumo Não Cíclico.

Em síntese, os resultados convergem para os achados de estudos anteriores, pois evidenciaram que ser auditado por uma Big Four reduz as chances de se receber um relatório modificado. Entre as explicações para tal efeito, podem-se citar: a reputação do auditor e o seu poder de persuasão sobre os gestores e contadores por seguirem as práticas sugeridas pelos mesmos (PERREAULT e KIDA, 2011). Empresas de auditoria do tipo Big Four possuem uma estrutura de treinamento e gestão do conhecimento que fortalece a capacidade de acumular e transferir conhecimento a terceiros, reforçando uma imagem positiva para seus clientes auditados, o que estimula a maior aceitação por parte dos clientes, impedindo ressalvas e outras qualificações. Além disso, a estrutura de governança das empresas afeta a estrutura de controle, reduzindo a possibilidade de que alguma prática de contabilidade inadequada seja utilizada.

No que se refere à redução, as correlações entre a variação das receitas, ROA e a probabilidade de se receber uma opinião modificada seguem a expectativa teórica, pois foram negativamente correlacionadas.

Em termos de influência na probabilidade de se receber uma opinião modificada, podese associar às hipóteses de gerenciamento de resultados propostas por Lopes (2012). Entretanto, em termos médios, a variação das receitas observadas nessa amostra foi positiva, sugerindo que empresas com tendência de crescimento do volume de operações reduzem as chances de receberem um relatório modificado. A mesma explicação pode estar associada ao efeito do ROA, já que empresas com resultados positivos tendem a não precisar manipular informações para agradar ao mercado; isso reduz a possibilidade de se receber um relatório modificado, entretanto, apesar da significância estatística de ambas, em termos marginais, o efeito foi irrelevante, pois foi próximo de 0 (zero).

Entre as variáveis que aumentam as chances de uma empresa participante da $[\mathrm{B}]^{3}$ receber uma opinião modificada, observou-se que o tamanho da empresa majora essa possibilidade, o que se justifica, porque estas grandes empresas possuem quantidade maior de recursos e ativos; logo, a probabilidade de ocorrerem problemas decorrentes do conflito de agência é maior. No entanto, em termos marginais, o efeito é baixo, de $0,43 \%$. Sobre esse aspecto, alguns estudos encontram um efeito positivo do tamanho, uma vez que, supostamente, essas empresas estarão mais propensas à discricionariedade nas acumulações (Accruals), além de possuírem maior volume de ativos para o gerenciamento (LAWRENCE e MINUTT-MEZA, 2011; LAI, 2013). O mesmo efeito teve a quantidade de parágrafos de ênfase. Sabe-se que, após a adoção das normas internacionais de contabilidade, os relatórios de auditoria aumentaram de tamanho; além disso, o número de ênfases desses relatórios ampliou, ora para dar maior clareza às bases e escopo do trabalho feito, ora para se destacarem pontos relevantes, mas que não se enquadram no conceito de ressalvas. Todavia, com o aumento do número de ênfases, podem-se esperar, em decorrência do maior julgamento trazido pela adoção das IFRS (BALL, 2006), pontos de discordância e que talvez acarretem ressalvas, iniciando com ênfases e, posteriormente, em ressalvas, dada à efetivação de discordância por parte dos auditores, em consequência de um evento que outrora ensejara apenas uma ênfase.

Outros dois fatores que aumentam as chances de se receber uma opinião modificada foram a divulgação de prejuízo e a adoção das IFRS. No primeiro caso, têm-se evidências de que os gestores tendem a buscar reduzir o efeito de notícias ruins no mercado; logo, a apresentação de prejuízo pode incitar o gestor a manipular as informações, afetando a chance de se receber uma opinião modificada. No que se refere à adoção inicial das IFRS (parcial), tal efeito era esperado, pois, com a adoção desse padrão, o julgamento responsável e a essência sob a forma podem afetar na interpretação e aplicação das IFRS; portanto, há de se esperar maior divergência entre os contadores e auditores (LAI, 2013), aumentando a possibilidade de 
emissão de opinião modificada. Além disso, a maior percepção de risco de auditoria pode induzir o auditor à maior chance de emitir um relatório modificado. Como aumentou o julgamento profissional, espera-se maior percepção do risco de auditoria; assim, potencialmente, esse ambiente pode afetar a propensão ao aumento de emissão de uma opinião modificada (ASARE, COHEN e TROMPETER, 2005). Em termos marginais, observou-se que a adoção das IFRS aumentou em 3,23\% a probabilidade de se receber um parecer modificado, enquanto a divulgação de prejuízo amplia em 5,89\% tal probabilidade.

Por fim, percebeu-se que o ambiente de adoção da SOX em 2002 (efeito Enron) e estar no setor de Consumo Não Cíclico aumentam a chance de se receber uma opinião modificada. Em termos do efeito crise, o ambiente de instabilidade econômica provoca no mercado maior percepção de risco por parte dos diversos agentes econômicos, inclusive, dos auditores, por isso há de se esperar que, nesses períodos, aumente o número de relatórios modificados (SIKKA, 2009).

Por sua vez, apesar da Crise de 2002 ocorrida na Argentina, país que possui uma dependência econômica relevante em termos de balança comercial, pode-se esperar que as evidências aqui apresentadas quanto a essa variável causem o efeito decorrente do Caso Enron e da Promulgação da SOX (CHAN, LEE e SEOW, 2008; HOLLINGSWORTH e LI, 2012). No que se refere ao setor econômico, observou-se que o setor de Consumo Não Cíclico aumenta em 2,73\% as chances de se receber uma opinião modificada. Nesses setores, encontramos empresas dos segmentos de Agronegócios, Medicamentos, Serviços Médicos e outros ligados a ativos biológicos, ativos intangíveis e etc. Isso sugere maior propensão à qualificação do relatório pelos mesmos motivos ligados ao julgamento profissional. Logo, maior julgamento, maior risco de auditoria estimulam os auditores a emitirem opiniões modificadas (ALMEIDA e ALMEIDA, 2009). 
Tabela 2 - Estimativa do Modelo Logit de determinantes da opinião modificada dos auditores

\begin{tabular}{|c|c|c|c|c|c|c|c|c|c|c|c|c|}
\hline Período & \multicolumn{4}{|c|}{ 2002-2012 } & \multicolumn{4}{|c|}{$2002-2007$} & \multicolumn{4}{|c|}{ 2008-2012 } \\
\hline $\begin{array}{l}\text { Obs.: } \\
\text { LR }\left(X^{2}\right): \\
\text { Pseudo } R^{2}\end{array}$ & & & & $\begin{array}{r}4.708 \\
358,06^{*} \\
12,04 \%\end{array}$ & & & & $\begin{array}{r}2.275 \\
180,81^{*} \\
11,04 \%\end{array}$ & & & & $\begin{array}{r}2.416 \\
173,35^{*} \\
13,22 \%\end{array}$ \\
\hline Topin & Coef. & $\begin{array}{l}\text { Razão de } \\
\text { Chances }\end{array}$ & $\begin{array}{c}\text { Efeito } \\
\text { Marginal } \\
\end{array}$ & $\mathbf{P}>|\mathbf{z}|$ & Coef. & $\begin{array}{c}\text { Razão de } \\
\text { Chances }\end{array}$ & $\begin{array}{c}\text { Efeito } \\
\text { Marginal }\end{array}$ & $\mathbf{P}>|\mathbf{z}|$ & Coef. & $\begin{array}{c}\text { Razão de } \\
\text { Chances } \\
\end{array}$ & $\begin{array}{c}\text { Efeito } \\
\text { Marginal } \\
\end{array}$ & $\mathbf{P}>|\mathbf{z}|$ \\
\hline Intercepto & $-3,12$ & 0,04 & & $0,00^{*}$ & $-2,65$ & 0,07 & & $0,00^{*}$ & $-3,17$ & 0,04 & & $0,00^{*}$ \\
\hline Big Four & $-0,64$ & 0,53 & $-4,05 \%$ & $0,00^{*}$ & $-0,55$ & 0,57 & $-1,89 \%$ & $0,00^{*}$ & $-0,76$ & 0,47 & $-3,96 \%$ & $0,00^{*}$ \\
\hline MudAudit & 0,08 & 1,09 & $0,50 \%$ & 0,48 & 0,15 & 1,17 & $0,56 \%$ & 0,31 & $-0,05$ & 0,95 & $0,00 \%$ & 0,80 \\
\hline Qtde. Parágrafos de Ênfase & 0,11 & 1,12 & $0,66 \%$ & $0,0471^{* *}$ & & & & & 0,09 & 1,10 & $0,00 \%$ & 0,11 \\
\hline Tamanho & 0,07 & 1,08 & $0,43 \%$ & $0,00^{*}$ & 0,07 & 1,07 & $0,22 \%$ & $0,001 *$ & 0,08 & 1,08 & $0,04 \%$ & $0,002 *$ \\
\hline$\Delta$ Receitas & $-0,05$ & 0,95 & $-0,27 \%$ & $0,027^{* *}$ & $-0,05$ & 0,95 & $-0,16 \%$ & 0,12 & $-0,05$ & 0,95 & $0,00 \%$ & 0,12 \\
\hline Nível de Endividamento & $-0,00$ & 1,00 & $0,00 \%$ & 0,43 & $-0,00$ & 1,00 & $-0,01 \%$ & 0,40 & $-0,00$ & 1,00 & $0,00 \%$ & 0,55 \\
\hline ROA & $-0,00$ & 1,00 & $0,00 \%$ & $0,055^{* * *}$ & 0,00 & 1,00 & $0,00 \%$ & 0,88 & $-0,00$ & 1,00 & $0,00 \%$ & $0,044 * *$ \\
\hline Prejuízo & 0,85 & 2,35 & $5,89 \%$ & $0,00^{*}$ & 0,91 & 2,47 & $3,64 \%$ & $0,00^{*}$ & 0,88 & 2,40 & $4,74 \%$ & $0,00^{*}$ \\
\hline$\Delta$ Resultado & $-0,00$ & 0,99 & $0,00 \%$ & 0,46 & $-0,00$ & 1,00 & $0,00 \%$ & 0,47 & $-0,00$ & 1,00 & $0,00 \%$ & 0,73 \\
\hline Nível de Governança & $-1,33$ & 0,26 & $-6,08 \%$ & $0,00 *$ & $-1,10$ & 0,33 & $-2,87 \%$ & $0,00^{*}$ & $-1,72$ & 0,18 & $-5,86 \%$ & $0,00^{*}$ \\
\hline Pré IFRS & 0,42 & 1,53 & $2,48 \%$ & 0,12 & & & & & & & & \\
\hline IFRS Parcial & 0,49 & 1,63 & $3,23 \%$ & $0,05 * *$ & & & & & 0,51 & 1,67 & $0,02 \%$ & $0,044 * *$ \\
\hline Adoção Inicial IFRS Full & 0,15 & 1,16 & $0,92 \%$ & 0,57 & & & & & 0,18 & 1,20 & $0,87 \%$ & 0,49 \\
\hline SOX & 0,82 & 2,27 & $6,59 \%$ & $0,00^{*}$ & 0,77 & 2,16 & $3,34 \%$ & $0,001 *$ & & & & \\
\hline Dummy para ano & & Sim & & & & Sim & & & & Sim & & \\
\hline Dummy para o setor & & Sim & & & & Sim & & & & Sim & & \\
\hline Teste Hosmer-Lemeshow & Pearson $\mathrm{X}^{2}$ : & $4.332,77$ & Prob $>X^{2}:$ & 0,9068 & Pearson $\mathrm{X}^{2}$ : & 2112,78 & Prob $>X^{2}:$ & 0,4361 & Pearson $\mathrm{X}^{2}$ : & 2207,02 & Prob $>X^{2}:$ & 0,9532 \\
\hline Classificação correta & & $90,42 \%$ & & & & $88,22^{\circ}$ & & & & $92,43 \%$ & & \\
\hline Área sob a curva ROC & & $75,07 \%$ & & & & $73,87^{\circ}$ & & & & $76,17 \%$ & & \\
\hline Probabilidade média & & $6,20 \%$ & & & & $3,41 \%$ & & & & $4,72 \%$ & & \\
\hline
\end{tabular}

Probabilidade média

$6,20 \%$

$3,41 \%$

$4,72 \%$

Fonte: Dados da Pesquisa 


\section{Considerações Finais}

O objetivo do presente trabalho foi identificar o efeito Big Four sobre a probabilidade de se receber uma opinião modificada do auditor, bem como estimar a probabilidade média de se receber uma opinião modificada. Para tanto, analisaram-se dados de 504 empresas participantes no mercado de capitais no período de 2002 a 2012. O estudo, de natureza descritiva, documental e com abordagem quantitativa, utilizou a análise de regressão com dados em corte transversal agrupado através de um modelo logístico. Os resultados evidenciaram que, ao longo do período, as Big Four predominaram na emissão de relatórios às empresas participantes da amostra. Esse crescimento se intensificou por volta de 2008, a partir da adoção das normas internacionais de contabilidade (IFRS), totalizando em 79\% de relatórios emitidos pelas Big Four. A distribuição das empresas participantes da $[\mathrm{B}]^{3}$ que fizeram parte da amostra $(97 \%$ do total) entre os auditores apresenta-se concentrada, sendo que $61 \%$ dos relatórios analisados foram emitidos pelas Big Four, 16\% por quatro empresas nacionais e o restante por aproximadamente 130 empresas nacionais.

Os resultados evidenciaram que ser auditado por uma Big Four reduz a probabilidade de se obter uma opinião modificada, logo, rejeitou-se a hipótese desenvolvida $\left(\mathrm{H}_{1}\right)$. Em termos médios, as empresas participantes da amostra têm $6,20 \%$ de chance de receberem um relatório modificado. Além disso, os resultados evidenciaram que, entre as variáveis que reduzem a probabilidade de se receber uma opinião modificada, destacaram-se: (1) Variação das receitas, (2) Retorno sobre Ativos, (3) Variação do resultado, (4) estar nos Níveis de Governança e (5) ser do setor financeiro. Já as variáveis que aumentam a probabilidade de se receber uma opinião modificada, identificaram-se na: (6) quantidade de $\S \S$ de ênfase, (7) tamanho da empresa, (8) apresentação de prejuízo, (9) adoção parcial das IFRS, (10) SOX, (11) o ano de 2003 e (12) estar no setor de Consumo Cíclico. Os resultados são convergentes com estudos anteriores como os de Li, Song e Wong (2008); Almeida e Almeida (2008); Francis e Yu (2009); Camargo et al. (2012); Gaganis, Pasiouras e Doumpos (2007); Manry, Tiras e Wheatley (2003); Louis (2005), dentre outros mencionados ao longo do trabalho.

Os resultados contribuem com os reguladores, investidores e auditores na sinalização dos fatores que mais afetam o tipo de opinião do auditor no contexto brasileiro, haja vista que os estudos anteriores não avaliaram um conjunto de dados com a amplitude da presente análise. Apesar disso, o estudo apresenta algumas limitações ligadas à ausência de variáveis significativas e o possível efeito de endogeneidade. Isso porque questões como a identificação da estrutura de governança especificamente adotada, a existência de um comitê de auditoria, independência do conselho de administração, gerenciamento de resultados e outras proxies de qualidade da informação podem afetar a probabilidade de chances de se receber um parecer modificado. Logo, sugere-se, para estudos futuros, a inclusão de outras variáveis como as mencionadas e, além disso, a utilização de um modelo logístico multinominal ou dados em painel podem melhorar a capacidade explicativa ou a significância das variáveis.

\section{Referências}

ABUGHAZALEH, N.; O'CONNELL, V.; PRINCEN, J. Audit Quality, Auditor Size and Legal Environments. Quarterly Journal of Finance and Accounting, v. 53, n. 3-4, Summer-Autum 2015. 39-78. Disponivel em: <http://www.qjbe.unl.edu/>. Acesso em: 23 Fevereiro 2015.

ALMEIDA, J. E. F.; ALMEIDA, J. C. G. Auditoria e earnings management: um estudo empírico nas empresas abertas auditadas pelas big four e demais firmas de auditoria. Revista Contabilidade \& Finanças, v. 20, n. 50, mai/ago 2009. 62-74. 
ALMEIDA, K. K. N.; VASCONCELOS, M. T. C. Conteúdo informativo do parecer dos auditores independentes sobre demonstrações contábeis de empresas Brasileiras. In Congresso ANPCONT - Associação Nacional dos Programas de Pós-graduação em Contabilidade. Gramado: [s.n.]. Anais..., 2007. p. 1-15.

ASARE, S.; COHEN, J.; TROMPETER, G. The effect of non-audit services on client risk, acceptance and staffing. Journal of Accounting and Public Policy, v. 24, n. 6, Nov-Dec 2005. 489-520. http://dx.doi.org/10.1016/j.jaccpubpol.2005.10.003

ASTHANA, S.; BALSAM, S.; KIM, S. The effect of Enron, Andersen, and Sarbanes-Oxley on the US market for audit services. Accounting Research Journal, v. 22, n. 1, 2009. 4-26. http://dx.doi.org/10.1108/10309610910975306

AUTORE, D. M.; BILLINGSLEY, R. S.; SCHNELLER, M. I. Information uncertainty and auditor reputation. Journal of Banking \& Finance, v. 33, p.183-192, 2009. doi.org/10.1016/j.jbankfin.2008.07.011

AZEVEDO, F. B.; COSTA, F. M. Efeito Troca da Firma de Auditoria no Gerenciamento de Resultados das Companhias Abertas Brasileiras. RAM - Revista de Administração da Mackenzie, São Paulo, v. 13, n. 5, Set/Out. 2012. 65-100. Disponivel em: $<$ http://www.scielo.br/pdf/ram/v13n5/v13n5a04.pdf.>. Acesso em: 23 Mar 2015.

BALL, R. International Financial Reporting Standards (IFRS): Pros and Cons for Investors. Accounting and Business Research, v. 36, n. 1, 2006. 5-27. http://dx.doi.org/10.1080/00014788.2006.9730040

BARTON, J. Who Cares about Auditor Reputation. Contemporary Accounting Research, v. 22, n. 2, 2005. 549-586. http://dx.doi.org/10.1506/C27U-23K8-E1VL-20R0

BEAVER, W. H. Financial Reporting: an accounting revolution. 3a.Ed. ed. New Jersey: Prentice Hall, 1998. p.180 p.

BLANDON, J. G.; ARGILES, J. M. Audit firm tenure and independence: A comprehensive investigation of audit qualifications in Spain. Journal of International Accounting, Auditing and Taxation, 2015. 82-93. http://dx.doi.org/10.1016/j.intaccaudtax.2015.02.001.

BLANDON, J. G.; BOSCH, J. M. A. Audit firm tenure and qualified opinions: New evidence from Spain. Revista de Contabilidad, v. 16, n. 2, 2013. 118-125. http://dx.doi.org/10.1016/j.rcsar.2013.02.001.

BLAY, A. D.; GEIGER, M. A. Auditor Fees and Auditor Independence: Evidence From Going Concern Reporting Decisions. Contemporary Accounting Research, 2012. http://dx.doi.org/10.1111/j.1911-3846.2012.01166.x.

BOONE, J. P.; KHURANA, I. K.; RAMAN, K. K. Audit Market Concentration and Auditor Tolerance for Earnings Management. Contemporary Accounting Research, v. 29, n. 4, Winter 2012. 1171-1203. http://dx.doi.org/10.1111/j.1911-3846.2011.01144.x

BOYNTON, W. C.; JOHNSON, R. N.; KELL, W. G. Auditoria. São Paulo: Atlas, 2002. 
BRICKLEY, J. A.; ZIMMERMAN, J. L. Corporate Governance Myths: Comments on Armstrong, Guay, and Weber. Journal of Accounting and Economics, 50, n. 2, 2010. 235245. https://doi.org/10.1016/j.jacceco.2010.10.002

BROWN, P.; BEEKES, W.; VERHOEVEN, P. Corporate governance, accounting and finance: A review. Accounting \& Finance, 51, n. 1, March 2011. 96-172. https://doi.org/10.1111/j.1467-629X.2010.00385.x

BYINGTON, J. R.; GUTTON, S. G. The self-regulating profession: An analysis of the political monopoly tendencies of the audit profession. Critical Perspectives on Accounting, 2, n. 4, 1991. 315-330. https://doi.org/10.1016/1045-2354(91)90006-Y

CAMARGO, R. V. W. et al. Determinantes dos pareceres dos auditores independentes emitidos às companhias negociadas na BM\&F Bovespa. In Congresso USP de Controladoria e Contabilidade. São Paulo: [s.n.]. Anais... 2012. p. 1-20. 26 e 27 julho.

CAO, Z.; FEROZ, E. H.; DAVALOS, S. V. Corporate governance and default risk of firms cited in the SEC's Accounting and Auditing Enforcement Releases. Rev Quant Finan Acc, 44, 2015. 113-138. https://doi.org/10.1007/s11156-013-0401-9

CFC, C. F. D. C. Normas brasileiras de contabilidade: NBC TA - de auditoria independente: NBC TA estrutura. Brasília: Conselho Federal de Contabilidade, 2012. Acesso em: $20 \mathrm{Fev}$ 2015.

CHAN, K. C. C.; LEE, P.; SEOW, G. S. Why did management and auditors fail to identify ineffective internal controls in their initial SOX 404 reviews? Review of Accounting and Finance, 7, n. 4, 2008. 338-354. https://doi.org/10.1108/14757700810920757

CHANG, X.; DASGUPTA, S.; HILARY, G. The Effect of Auditor Quality on Financing Decisions. The Accounting Review, 84, n. 4, 2009. 1085-1117. https://doi.org/10.2308/accr.2009.84.4.1085

CHEN, C. J. P.; SRINIDHI, B.; SU, X. Effect of auditing: Evidence from variability of stock returns and trading volume. China Journal of Accounting Research, n. 7, 2014. 223-245. https://doi.org/10.1016/j.cjar.2014.11.002

CHEN, P. F. et al. The information role of audit opinions in debt contracting. Journal of Accounting and Economics, 61, 2016. 121-144. https://doi.org/10.1016/j.jacceco.2015.04.002

COASE, R. H. The nature of firm. Economica, 4, n. 16, November 1937. 386-405. Disponível em: http://links.jstor.org/sici?sici=00130427\%28193711\%292\%3A4\%3A16\%3C386\%3ATNOTF\%3E2.0.CO\%3B2-B . Acessado em: 17/09/2015.

COMPRIX, J.; HUANG, H. Does auditor size matter? Evidence from small audit firms. Advances in Accounting, incorporating Advances in International Accounting, n. 31, 2015. 11-20. https://doi.org/10.1016/j.adiac.2015.03.007 
COOPER, D. J. et al. Globalization and nationalism in a multinational accounting firm: The case of opening new markets in Eastern Europe. Accounting, Organizations and Society, 5, n. 23, 1998. 521-548. https://doi.org/10.1016/S0361-3682(98)00026-9

COOPER, D. R.; SCHINDLER, P. S. Métodos de pesquisa em administração. 7a. ed. Porto Alegre: Bookman, 2003. 640 p.

CRASWELL, A.; STOKES, D. J.; LAUGHTON, J. Auditor independence and fee dependence. Journal of Accounting and Economics, 33, 2002. 253-275. https://doi.org/10.1016/S01654101(02)00044-7

CULLINAN, C. P. et al. Audit opinion improvement and the timing of disclosure. Advances in Accounting, incorporating Advances in International Accounting, 28, 2012. 333-343. https://doi.org/10.1016/j.adiac.2012.09.010

DANG, L.; BROWN, K. F.; MCCULLOUGH, B. D. Apparent audit failures and value relevance of earnings and book value. Review of Accounting and Finance, 10, n. 2, 2011. 134-154. https://doi.org/10.1108/14757701111129616

DANTAS, J. A. et al. Determinações de Refazimento/Republicação de Demonstrações Financeiras pela CVM: O papel dos auditores independentes. Revista Universo Contábil, Blumenau, 7, n. 2, abr./jun. 2011. 45-64.

DART, E. UK investors' perceptions of auditor independence. The British Accounting Review, n. 43, 2011. 173-185. https://doi.org/10.1016/j.bar.2011.06.003

DEFOND, M. L.; LENNOX, C. S. The effect of SOX on small auditor exits and audit quality. Journal of Accounting and Economics, n. 52, $2011.21-40$. https://doi.org/10.1016/j.jacceco.2011.03.002

DEFOND, M.; ZHANG, J. A review of archival auditing research. Journal of Accounting, 58, 2014. 275-326. https://doi.org/10.1016/j.jacceco.2014.09.002

DI PIETRA, R.; MCLEAY, S.; RONEN, J. Accounting and Regulation: new insigths on governance, markets and institutions. New York: Springer, 2014. 412 p.

EBRAHIM, A. Audit fee premium and auditor change: the effect of Sarbanes-Oxley Act.

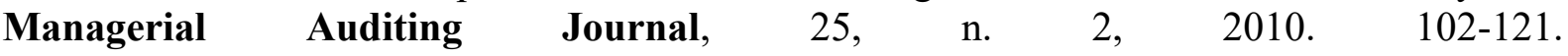
https://doi.org/10.1108/02686901011008936

EISEMBERG, T.; MACEY, J. R. Was Arthur Andersen Different? An empirical examination of major accounting firm audits of large clients. Journal of Empirical Legal Studies, 2, n. 1, 2004. 263-300. Disponível em: http://scholarship.law.cornell.edu/facpub/968 . Acessado em: $17 / 09 / 2015$.

FARINHA, J.; VIANA, L. F. Board Structure and Modified Audit Opinions: Evidence from the Portuguese Stock Exchange. International Journal of Auditing, 13, 2009. 237-258. https://doi.org/10.1111/j.1099-1123.2009.00394.x 
FÁVERO, L.P. Análise de Dados: modelos de regressão com excel, stata e spss.1.ed. Rio de Janeiro: Elsevier, 2015.

FOSTER, B. P.; SHASTRI, T. Determinants of going concern opinions and audit fees for development stage enterprises. Advances in Accounting, incorporating Advances in International Accounting, 33, 2016. 68-84. https://doi.org/10.1016/j.adiac.2016.05.001

FRANCIS, J. R.; MICHAS, P. N.; YU, M. D. Office Size of Big 4 Auditors and Client Restatements. Contemporary Accounting Research, 30, n. 4, Winter 2013. 1626-1661. https://doi.org/10.1111/1911-3846.12011

FRANCIS, J. R.; YU, M. D. Big 4 Office Size and Audit Quality. The Accounting Review, 84, n. 5, Setembro 2009. 1521-1552. https://doi.org/10.2308/accr.2009.84.5.1521

GAGANIS, C.; PASIOURAS, F.; DOUMPOS, M. Probabilistic neural networks for the identification of qualified audit opinions. Expert Systems with Applications, 32, 2007. 114124. https://doi.org/10.1016/j.eswa.2005.11.003

GEORGE, J. S.; LIU, L. G. Independent audit committee characteristics and real earnings management. Managerial Auditing Journal, 29, n. 2, 2014. 153-172. https://doi.org/10.1108/MAJ-05-2013-0865

GIOELli, S. P. O.; CARVALHO, A. G.; SAMPAIO, J. O. Venture capital and earnings management in IPOs. BBR - Brazilian Business Review, Vitória, 10, n. 4, Out-Dez 2013. 30 64. http://dx.doi.org/10.15728/bbr.2013.10.4.2

GUJARATI, D. Econometria Básica. 4a.. ed. Rio de Janeiro: Elsevier, 2006.

HABIB, A. A meta-analysis of the determinants of modified audit opinion decisions. Managerial Auditing Journal, 28, n. 3, $2013 . \quad$ 184-216. https://doi.org/10.1108/02686901311304349

HE, L.; CHIANG, H. Market Reaction to Financial Statemen Restatement: A Study on the Information and Insurance Role of Auditors. Advances in Management and Applied Economics, 3, n. 4, 2013. 37-50. Disponível em: http://www.scienpress.com/Upload/AMAE/Vol\%203_4_4.pdf . Acessado em: 15/09/2015

HELIODORO, P. A.; CARREIRA, F. A.; LOPES, M. M. The change of auditor: The Portuguese case. Revista de Contabilidad - Spanish Accounting Review, 19, n. 2, 2016. 181 186. https://doi.org/10.1016/j.rcsar.2015.05.001

HERBOHN, K.; RAGUNATHAN, V. Auditor reporting and earnings management: some additional evidence. Accounting and Finance, 48, 2008. 575-601. https://doi.org/10.1111/j.1467-629X.2007.00256.x

HERZ, R. Navigating EU's complex auditor rotation rules. Compliance Week, 11, March 2014. 1-4. Disponivel em: <https://www.complianceweek.com.>. Acesso em: 10 Abril 2015. 
HOLLINGSWORTH, C.; LI, C. Investors'Perceptions of Auditors'Economic Dependence on the Client Pos-SOX Evidence. Journal of Accounting, Auditing \& Finance, 27, n. 1, 2012. 100-122. https://doi.org/10.1177/0148558X11409145

HOSMER, D. W.; LEMESHOW, S. Applied Logistic Regression. New York: WileyInterscience Publication, 2000. 2nd.

IANELLO, G. Non-Audit Services and Auditor Independence in the 2007 Italian Regulatory Environment. International Journal of Auditing, 16, 2012. 147-164. https://doi.org/10.1111/j.1099-1123.2012.00447.x

J.R., F.; MICHAS, P. N.; SEAVEY, S. E. Does Audit Market Concentration Harm the Quality of Audited Earnings? Evidence from Audit Markets in 42 Countries. Contemporary Accounting Research, Jun 2012. http://dx.doi.org/10.1111/j.1911-3846.2012.01156.x.

JENSEN, M. C.; MECKLING, W. H. Theory of the firm: managerial behavior, agency costs and ownership structure. Journal of Financial and Economics, 3, n. 4, October 1976. 305360. https://doi.org/10.1016/0304-405X(76)90026-X

JENSEN, M. C.; MECKLING, W. H. The nature of man. Journal of Applied Corporate Finance, Boston, 7, n. 2, 1994. 4-19. https://doi.org/10.1111/j.1745-6622.1994.tb00401.x

KHURANA, I. K.; RAMAN, K. K. Litigation Risk and the Financial Reporting Credibility of Big 4 versus Non-Big 4 Audits: Evidence from Anglo-American Countries. The Accounting Review, 79, n. 2, 2004. 473-495. Disponível em: http://www.jstor.org/stable/3203253. Acessado em: 20/04/2015.

KRANACHER, M. The audit opinion: choose our words carefully. The CPA Journal, Junho 2008. 80. Disponível em: http://archives.cpajournal.com/printversions/cpaj/2008/608/p80.htm . Acessado em: 20/04/2015.

KRAUß, P.; PRONOBIS, P.; ZULCH, H. Abnormal audit fees and audit quality: initial evidence from the German audit market. Journal of Business Economics, n. 85, 2015. 45-84. https://doi.org/10.1007/s11573-014-0709-5

KRYZANOWSKI, L.; ZHANG, Y. Financial restatements and Sarbanes-Oxley: Impact on Canadian firm governance and management turnover. Journal of Corporate Finance, 21, 2013. 87-105. https://doi.org/10.1016/j.jcorpfin.2013.01.007

LAI, K. H. Audit Reporting of Big 4 Versus Non-Big 4 Auditors: The Case of Ex-Andersen Clients. The International Journal of Accounting, 48, $2013.495-524$. https://doi.org/10.1016/j.intacc.2013.10.001

LAWRENCE, A.; MINUTT-MEZA, Z. P. Can Big \$ versus Non-Big 4 Differences in AuditQuality Proxies Be Attributed to Client Characteristicis? The Accounting Review, 86, n. 1, 2011. 259-286. https://doi.org/10.2308/accr.00000009 .

LENNOX, C.; LI, B. Accounting misstatements following law suits against auditors. Journal of Accounting and Economics, n. 57, 2014. 58-75. https://doi.org/10.1016/j.jacceco.2013.10.002 
LI, C.; SONG, F. M.; WONG, S. M. L. A continuous relation between audit firm size and audit opinions: evidence from China. International Journal of Auditing, n. 12, 2008. 111-127. https://doi.org/10.1111/j.1099-1123.2008.00374.x

LIN, Z.; JIANG, Y.; XU, Y. B. Do modified audit opinions have economic consequences? Empirical evidence based on financial constraints. China Journal of Accounting Research, 4, 2011. 135-154. https://doi.org/10.1016/j.cjar.2011.06.004

LOPES, A. B. Contabilidade e Finanças no Brasil: estudos em homenagem ao professor Eliseu Martins. São Paulo: Atlas, 2012.

LOUIS, H. Acquirers' abnormal returns and the non-Big 4 auditor clientele effect. Journal of Accounting and Economics, 40, 2005. 75-99. https://doi.org/10.1016/j.jacceco.2005.03.001

MALHOTRA, N. K. Pesquisas de marketing: uma orientação aplicada. Tradução de Laura Bocco. 4a. ed. Porto Alegre: Bookman, 2006. 720 p.

MANRY, D.; TIRAS, S. L.; WHEATLEY, C. M. The Influence of Interim Auditor Reviews on the Association of Returns with Earnings. The Accounting Review, 78, n. 1, January 2003. 251-274. Disponível: http://www.jstor.org/stable/3203303 . Acessado em 20/03/2015.

MARQUES, V. A. Qualidade das Informações Financeiras e o Ambiente Regulatório: Evidências Empíricas no Período de 1998-2013. (Doutorado em Administração) - Centro de Pós-Graduação e Pesquisas em Administração - CEPEAD, Universidade Federal de Minas Gerais (Tese de Doutorado). Belo Horizonte, p. f.220. 2016. Disponível: http://cepead.face.ufmg.br/btd/files/498/aid498n2a1.pdf . Acessado em 20/03/2017.

MARQUES, V. A. et al. O efeito Big Four sobre os tipos de relatórios de auditoria: evidências empíricas no mercado brasileiro. In V Congresso da Ordem dos Técnicos Oficiais de Contas de Portugal. Lisboa: [s.n.]. Anais... 2015. p. 1-20. Disponível: https://www.occ.pt/news/trabalhoscongv/pdf/70.pdf . Acessado em 20/05/2017.

MARQUES, V. A. et al. Relação entre Níveis de Governança, Política de Dividendos, Endividamento e Valor das Empresas. Revista Evidenciação Contábil \& Finanças, João Pessoa, 3, n. 2, maio/ago 2015. 4-26. https://doi.org/8405/RECFIN20150201

MCCRAKEN, S. A. Auditor's Strategies to Protect Their Litigation Reputation: A Research Note. Auditing: A Journal of Practice \& Theory, 22, n. 1, March 2003. 165-179. Disponivel em: http://aaapubs.org/doi/abs/10.2308/aud.2003.22.1.165 . Acessado em: 20/02/16.

MCHUGH III, M. E.; POLINSKI, P. W. Audit Firm Changes Post Sarbanes-Oxley. The CPA Journal, 82, n. 5, May 2012. 24-31. Disponivel em: http://www.nysscpa.org . Acessado em: 20/07/15.

MCKEE, T. E. Evaluating Fraud Risk During Auditing Planning. The CPA Journal, October 2014. 28-31. 
PARACINI, H. G.; MALSCH, B.; PAILLÉ, A. M. Fear and risk in the audit process. Accounting, Organizations and Society, 39, $2014.264-288$. https://doi.org/10.1016/j.aos.2014.02.001

PEI, P.; HAMILL, P. A. Do modified audit opinions for Shanghai listed firms convey heterogeneous information? Journal of International Accounting, Auditing and Taxation, n. 22, 2013. 1-11. https://doi.org/10.1016/j.intaccaudtax.2013.02.004

PERREAULT, S.; KIDA, T. The relative effectiveness of persuasion tactics in auditor-client negotiations. Accounting, Organizations and Society, 36, $2011.534-547$. https://doi.org/10.1016/j.aos.2011.09.001

PEYTCHEVA, M.; GILLETT, P. R. Auditor perceptions of prior involvement and reputation threats as antecedents of quality threatening audit behavior. Managerial Auditing Journal, 27, n. 9, 2012. 796-820. https://doi.org/10.1108/02686901211263058

PIOT, C. Auditor Reputation and Model of Governance: A Comparison of France, Germany and Canada. International Journal of Auditing, 9, n. 1, 2005. 21-44. https://doi.org/10.1111/j.1099-1123.2005.00100.x

RAGHUNANDAN, K.; READ, K. J.; WHISENANT, J. S. Initial Evidence on the Association between Nonaudit Fees and Restated Financial Statements. Accounting Horizons, 17, n. 3, September 2003. 223-234. https://doi.org/10.2308/acch.2003.17.3.223

RICARDINO, A.; CARVALHO, L. N. Breve retrospectiva do desenvolvimento das atividades de auditoria no Brasil. Revista Contabilidade \& Finanças, São Paulo, 15, n. 35, 2004. 22-34.

SANTOS, A. C. et al. Auditoria Independente: um estudo dos pareceres emitidos sobre demonstrações contábeis de empresas brasileiras listadas na Bovespa e Nyse. Revista Universo Contábil, Blumenau, 5, n. 4, out./dez. 2009. 44-62. https://doi.org/10.4270/ruc.2009430

SCOTT, W. D.; GIST, W. E. Forced auditor change, industry specialization and audit fees. Managerial Auditing Journal, 8, 2013. 708-734. https://doi.org/10.1108/MAJ-11-2012-0779

SERRA, S. A. E.; RODRÍGUEZ, M. F. R. Propensão para emitir relatórios de auditoria modificados: análise da variável reputação e nível de especialização do auditor. In Tourism and Management Studies International Conference. Algarve: [s.n.]. Proceedings...2012. p. 1-10. Disponivel em: www.tmstudies.net/index.php/ectms/article/download/483/847. Acessado em: 20/07/15.

SIKKA, P. Financial crisis and the silence of the auditors. Accounting, Organizations and Society, 34, 2009. 868-873. https://doi.org/10.1016/j.aos.2009.01.004

SMAILI, N.; LABELLE, R. Corporate governance and accounting irregularities: Canadian evidence. Journal of Management \& Governance, 3, $2016.625-653$. https://doi.org/10.1007/s10997-015-9314-4

SOLTANI, B. Timeliness of corporate and audit reports: Some empirical evidence in the French context. The International Journal of Accounting, 37, 2002. 215-246. https://doi.org/10.1016/S0020-7063(02)00152-8 
SUÁREZ, J. A. et al. The effectiveness of the audit committee in Spain: implications of its existence on the auditor's opinion. Journal of Spanish Economic Association, n. 4, 2013. 333-352. https://doi.org/10.1007/s13209-012-0094-7

SUNDER, S. Teoria da Contabilidade e do Controle. São Paulo: Atlas, 2014.

TOTH, A. Reputation Effects in the Markets of Certifiers: Evidence from auditing industry. Economic Inquiry, 52, n. 1, April 2014. 505-517. https://doi.org/10.1111/ecin.12063

TSIPOURIDOU, M.; SPATHIS, C. Earnings management and the role of auditors in an unusual IFRS context: The case of Greece. Journal of International Accounting, Auditing and Taxation, 21, 2012. 62-78. https://doi.org/10.1016/j.intaccaudtax.2012.01.005

TSIPOURIDOU, M.; SPATHIS, C. Audit opinion and earnings management: Evidence from Greece. Accounting Forum, Em impressão, $2013 . \quad 17 \mathrm{p}$. https://doi.org/10.1016/j.accfor.2013.09.002

VELOSO, A. C. C. et al. Auditando os Auditores: Motivações dos Processos Contra Auditores junto à Comissão de Valores Mobiliários no período de 2007-2013. Revista de Auditoria, Governança \& Contabilidade, Monte Carmelo, 3, 2015. 46-60. Disponivel em: $<$ http://www.fucamp.edu.br/editora/index.php/ragc/article/view/564/413. $>$. Acesso em: 10 Dezembro 2016.

WATTS, R. L. Accounting Choice Theory and Market-Based Research. Accounting. British Accounting Review, n. 24, 1992. 235-267. https://doi.org/10.1016/S0890-8389(05)80023-X

WOOLDRIDGE, J. M. Econometric analysis of cross section and data panel. 2nd. ed. Massachussets: Massachussets Institute of Technology, 2010. 1-1064 p.

XIE, J.; CAI, C.; YE, J. Abnormal Audit Fees and Audit Opinion - Further Evidence from China's Capital Market. China Journal of Accounting Research, 3, n. 1, 2010. 51-70. https://doi.org/10.1016/S1755-3091(13)60019-2

\section{Agradecimentos}

Os autores agradecem aos economistas Rodrigo Pimentel dos Santos e Audrey Verônica Freitas Nunes de Souza, na época, bolsistas de iniciação científica do projeto e à PROppg/PUC Minas pelo financiamento da pesquisa pelo FIP 2/2013. 